\title{
Light-powered Dissipative Assembly of Diazocine Coordination Cages
}

\section{Haeri Lee, ${ }^{1,2}$ Jacopo Tessarolo, ${ }^{1}$ Daniel Langbehn, ${ }^{3}$ Ananya Baksi, ${ }^{1}$ Rainer Herges, ${ }^{3}$ Guido H. Clever, ${ }^{1, *}$}

${ }^{1}$ Faculty of Chemistry and Chem. Biology, TU Dortmund University, Otto Hahn Str. 6, 44227 Dortmund, Germany.

${ }^{2}$ Dept. of Chemistry, Hannam University, 1646, Yuseong-daero, Yuseong-gu, Daejeon, 34054, Republic of Korea.

${ }^{3}$ Otto Diels Institute of Organic Chemistry, Christian Albrechts University, Otto Hahn Platz 4, 24118 Kiel, Germany.

\section{Supporting Information}

1. General procedures

2. Synthesis of ligands and palladium(II) assemblies

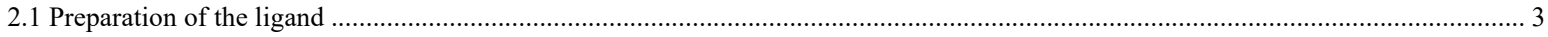

2.1 .1 (Z)-3,8-Bis(pyridin-3-ylethynyl)-11,12-dihydrodibenzo[c,g]-[1,2]diazocine (cis-L) .................................................... 3

2.1.2 (E)-3,8-Bis(pyridin-3-ylethynyl)-11,12-dihydrodibenzo[c,g]-[1,2]diazocine (trans-L) ...................................................... 5

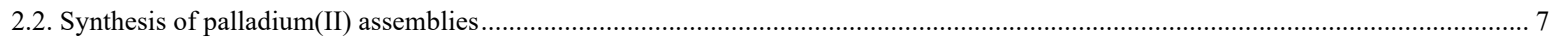

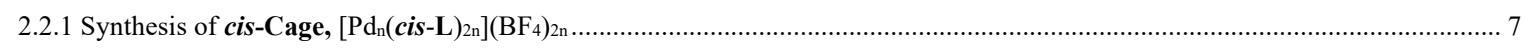

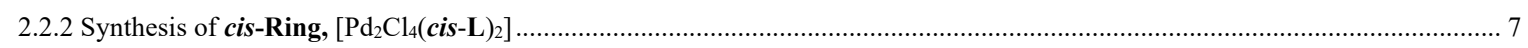

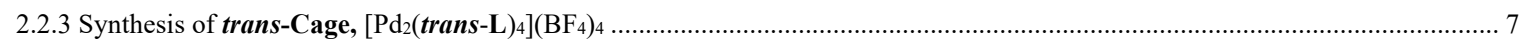

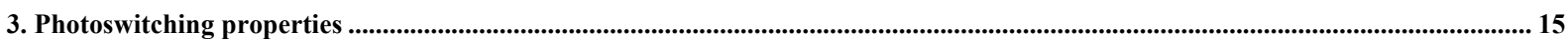

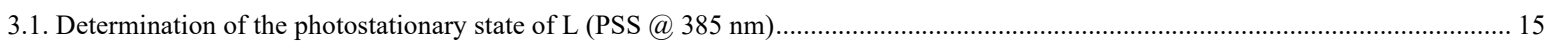

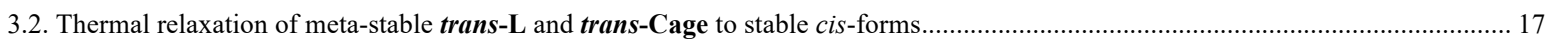

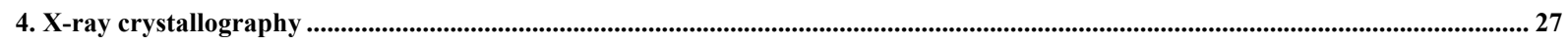

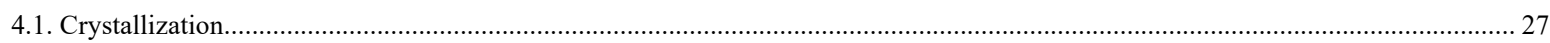

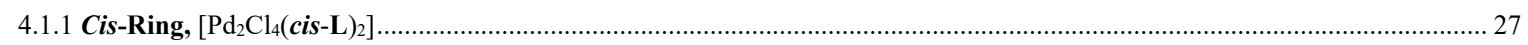

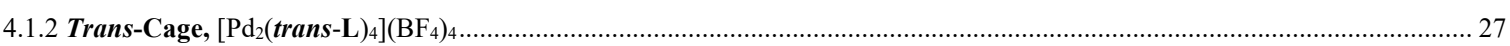

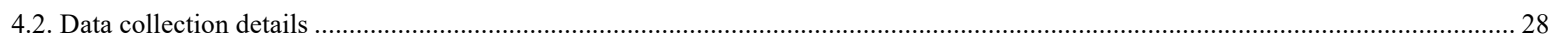

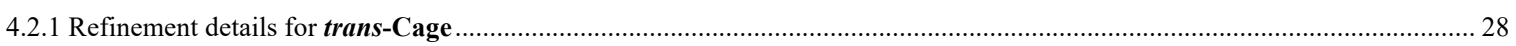

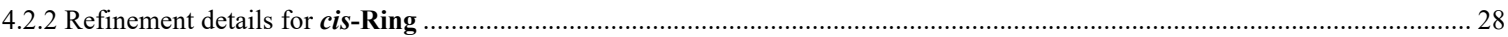

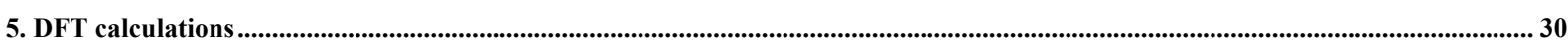

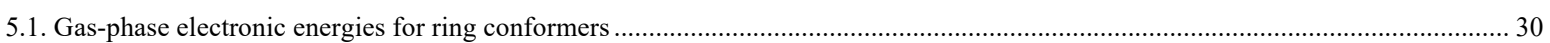

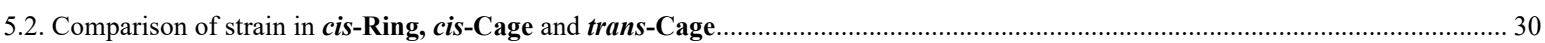

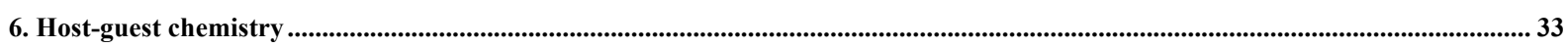

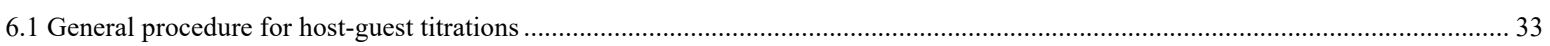

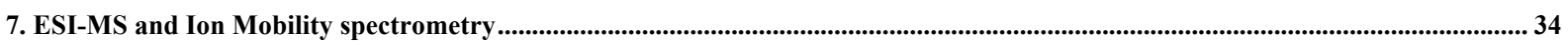

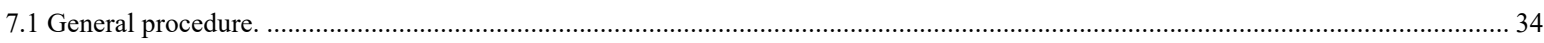

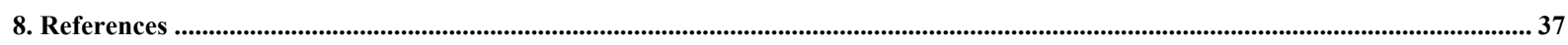




\section{General procedures}

All chemicals, except otherwise specified, were obtained from commercial sources and used without further purification. (Z)-3,8-Diiodo-11,12-dihydrodibenzo[c,g][1,2] diazocine ${ }^{[\mathrm{S} 1]}$ was prepared according to a literature procedure. The tetrabutyl ammonium salt of the guest was prepared according to a previously reported procedure. ${ }^{[\mathrm{S} 2]}$ Recycling gel permeation chromatography was performed on a JAI LC-9210 II NEXT GPC system equipped with Jaigel $1 \mathrm{H}$ and $2 \mathrm{H}$ columns in series using chloroform as the eluent (HPLC grade). NMR measurements were all conducted at $298 \mathrm{~K}$ on Avance-500 and Avance-600 instruments from Bruker and an INOVA $500 \mathrm{MHz}$ machine from Varian. Mass measurements were performed using a Bruker TIMS-TOF mass spectrometer equipped with an electrospray ionization (ESI) source and trapped ion mobility spectrometry (TIMS) set up. The irradiations at $385 \mathrm{~nm}$ and $530 \mathrm{~nm}$ were performed placing the NMR tubes or the cuvettes in front of LED lamps $(3 \mathrm{x} 1.4$ W Power LED, 25 nm, FWHM) from Sahlmann photonics, Kiel, or using fiber coupled LEDs (Power output $9.6 \mathrm{~mW}$ for $530 \mathrm{~nm}$ and $10.7 \mathrm{~mW}$ for $385 \mathrm{~nm}$ ) from Thor Labs. UV-Vis spectra were recorded on Agilent 8453 and Jasco V-750 UV-Visible spectrophotometers. 


\section{Synthesis of ligands and palladium(II) assemblies}

\subsection{Preparation of the ligand}

\subsection{1 (Z)-3,8-Bis(pyridin-3-ylethynyl)-11,12-dihydrodibenzo[c,g]-[1,2]diazocine (cis-L)}

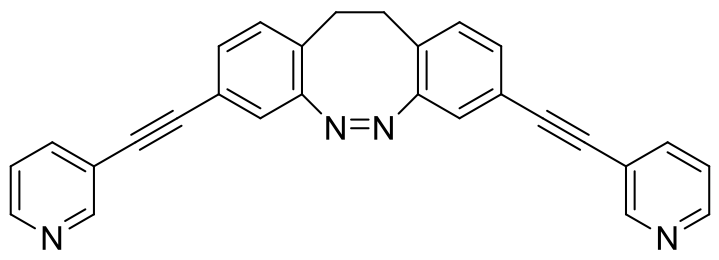

cis-L

To a stirred solution of (Z)-3,8-diiodo-11,12-dihydrodibenzo[c,g][1,2]diazocine (265 mg, 576 $\mu \mathrm{mol})$ in $50 \mathrm{~mL}$ toluene were added $\mathrm{CuI}(178 \mathrm{mg}, 28.8 \mu \mathrm{mol}), \mathrm{Pd}\left(\mathrm{PPh}_{3}\right)_{2} \mathrm{Cl}_{2}(40.0 \mathrm{mg}, 57.6$ $\mu \mathrm{mol})$ and triethylamine $(25 \mathrm{~mL})$. The reaction mixture was stirred for $20 \mathrm{~min}$ before addition of 3-ethynylpyridine (178 mg, $1.73 \mathrm{mmol})$. After further stirring at $50{ }^{\circ} \mathrm{C}$ for $3 \mathrm{~h}$ and cooling to room temperature, the mixture was filtrated over Celite and the solvent was evaporated under reduced pressure. The precipitate was purified by flash column chromatography (cyclohexane/ethyl acetate, $5 \% \rightarrow 80 \%$ ) to afford the product as a yellow solid $(90.0 \mathrm{mg}, 219$ $\mu \mathrm{mol}, 38 \%) .{ }^{1} \mathrm{H}$ NMR $\left(600 \mathrm{MHz}, \mathrm{DMF}-d_{7}, 298 \mathrm{~K}\right) \delta 8.76\left(\mathrm{~d},{ }^{4} J=1.7 \mathrm{~Hz}, 2 \mathrm{H}\right), 8.61\left(\mathrm{dd},{ }^{3} J=\right.$ $\left.4.9,{ }^{4} \mathrm{~J}=1.7 \mathrm{~Hz}, 2 \mathrm{H}\right), 7.98\left(\mathrm{dt},{ }^{3} J=7.9,{ }^{4} \mathrm{~J}=1.9 \mathrm{~Hz}, 2 \mathrm{H}\right), 7.48\left(\mathrm{ddd},{ }^{3} J=7.9,4.8,{ }^{4} \mathrm{~J}=0.9 \mathrm{~Hz}\right.$, 2H), $7.34\left(\mathrm{dd},{ }^{3} J=7.9,{ }^{4} J=1.7 \mathrm{~Hz}, 2 \mathrm{H}\right), 7.26\left(\mathrm{~d},{ }^{3} J=7.9 \mathrm{~Hz}, 2 \mathrm{H}\right), 7.18\left(\mathrm{~d},{ }^{4} J=1.7 \mathrm{~Hz}, 2 \mathrm{H}\right)$, $2.98\left(\mathrm{~d},{ }^{4} \mathrm{~J}=2.5 \mathrm{~Hz}, 4 \mathrm{H}, \mathrm{C}_{2} H_{4}\right)$. Diffusion coefficient $4.35 \times 10^{-10} \mathrm{~m}^{2} / \mathrm{s}$, DOSY-derived hydrodynamic radius $5.84 \AA$ in DMF- $d_{7}$ at $298 \mathrm{~K} .{ }^{13} \mathrm{C}$ NMR $(151 \mathrm{MHz}, \mathrm{DMF}, 298 \mathrm{~K}) \delta 155.71$, 151.98, 149.31, 138.61, 130.74, 130.47, 129.83, 123.87, 123.64, 121.23, 121.02, 119.66, 91.18, 86.72, 31.02. MS (EI, 70eV): $m / z(\%)=410$ (42), 382 (100), 303 (23), 266 (18). MS (EI, HR, $70 \mathrm{eV}): \mathrm{C}_{28} \mathrm{H}_{18} \mathrm{~N}_{4}, m / z=$ calc.: 410.15315 , found: 410.15218 . 


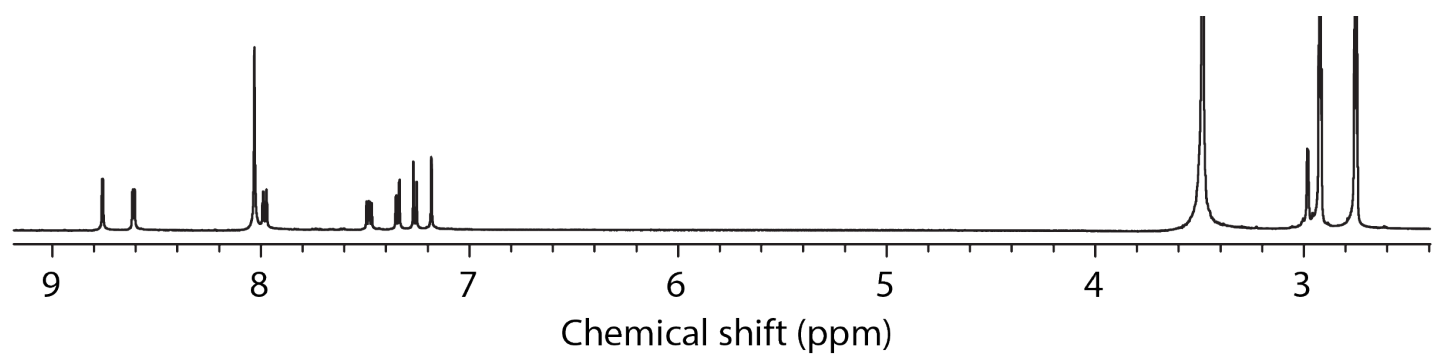

Figure S1. ${ }^{1} \mathrm{H}$ NMR spectrum (600 MHz, DMF-d7, 298K) of cis-L.

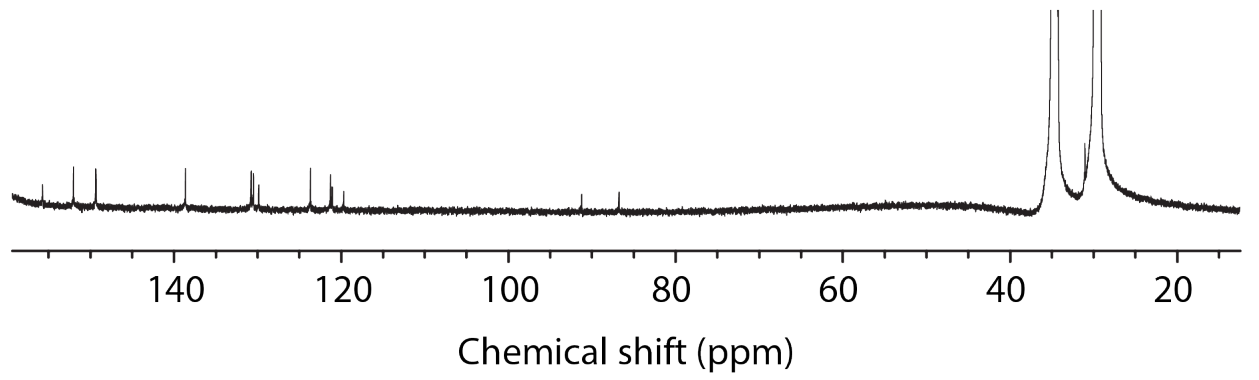

Figure S2. ${ }^{13} \mathrm{C}$ NMR spectrum (151 MHz, DMF- $\left.d_{7}, 298 \mathrm{~K}\right)$ of $\boldsymbol{c i s}-\mathbf{L}$.

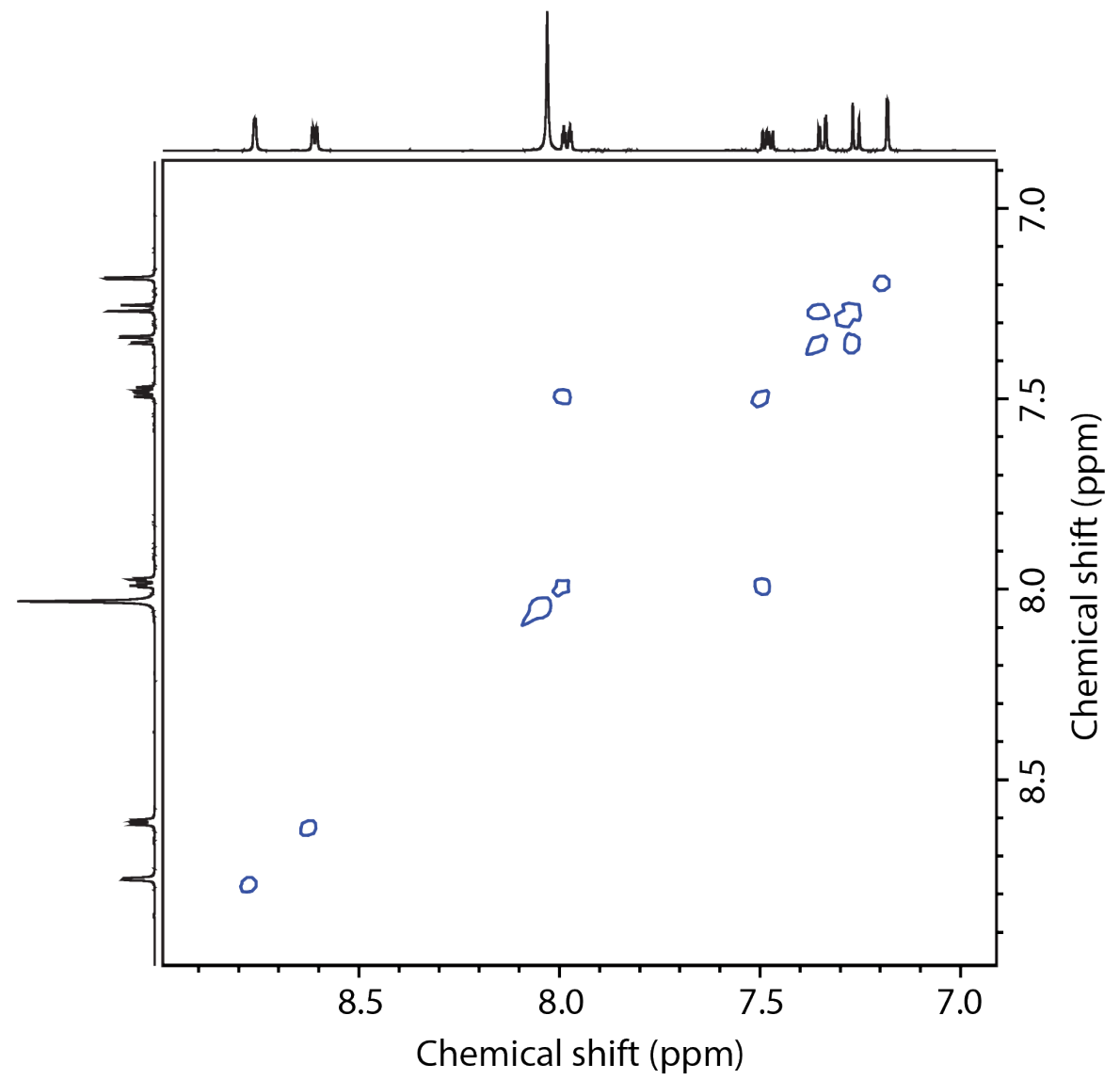

Figure S3. ${ }^{1} \mathrm{H}-{ }^{1} \mathrm{H}$ COSY spectrum (600 MHz, DMF- $\left.d_{7}, 298 \mathrm{~K}\right)$ of cis-L. 


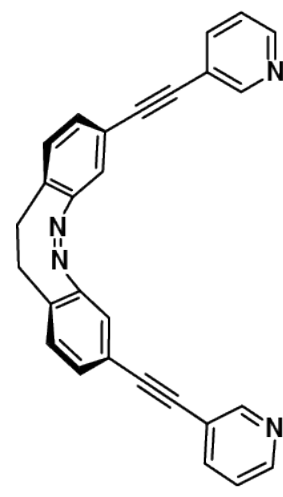

cis-L

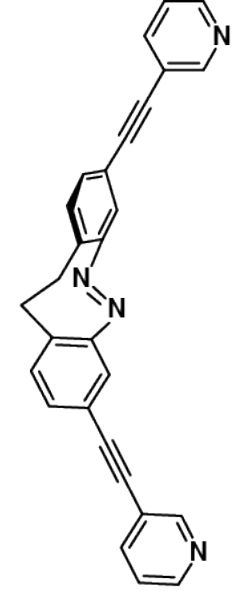

trans-L

Scheme S1. Interconversion between cis-L and trans-L by light and thermal relaxation

The metastable trans-form of ligand trans-L was obtained directly from cis-L by $385 \mathrm{~nm} \mathrm{UV}$ irradiation at RT, as a mixture containing $62 \%$ trans-L and $38 \%$ cis-L upon reaching the photostationary state (as determined by NMR and UV-vis spectroscopy). ${ }^{1} \mathrm{H}$ NMR (500 MHz, DMF- $d 7,298 \mathrm{~K}) \delta=8.86\left(\mathrm{~d},{ }^{4} J=1.4 \mathrm{~Hz}, 2 \mathrm{H}\right), 8.66\left(\mathrm{dd},{ }^{4} J=1.6,{ }^{3} J=4.8 \mathrm{~Hz}, 2 \mathrm{H}\right), 8.08\left(\mathrm{td},{ }^{4} J\right.$ $\left.=1.9,{ }^{3} J=7.9 \mathrm{~Hz}, 2 \mathrm{H}\right), 7.92\left(\mathrm{~d},{ }^{4} J=1.6 \mathrm{~Hz}, 2 \mathrm{H}\right), 7.58\left(\mathrm{dd},{ }^{4} J=1.7,{ }^{3} J=7.9 \mathrm{~Hz}, 2 \mathrm{H}\right), 7.55$ (ddd, $\left.{ }^{4} J=0.9,{ }^{3} J=4.9,7.9 \mathrm{~Hz}, 2 \mathrm{H}\right), 7.37\left(\mathrm{~d},{ }^{3} J=7.9 \mathrm{~Hz}, 2 \mathrm{H}\right), 2.89$ (br, 4H, $\mathrm{C}_{2} \mathrm{H}_{4}$ ), Diffusion coefficient $6.22 \times 10^{-10} \mathrm{~m}^{2} / \mathrm{s}$ for trans-L, DOSY-derived hydrodynamic radius $4.08 \AA$ in DMF$d_{7}$ at $298 \mathrm{~K} .$.

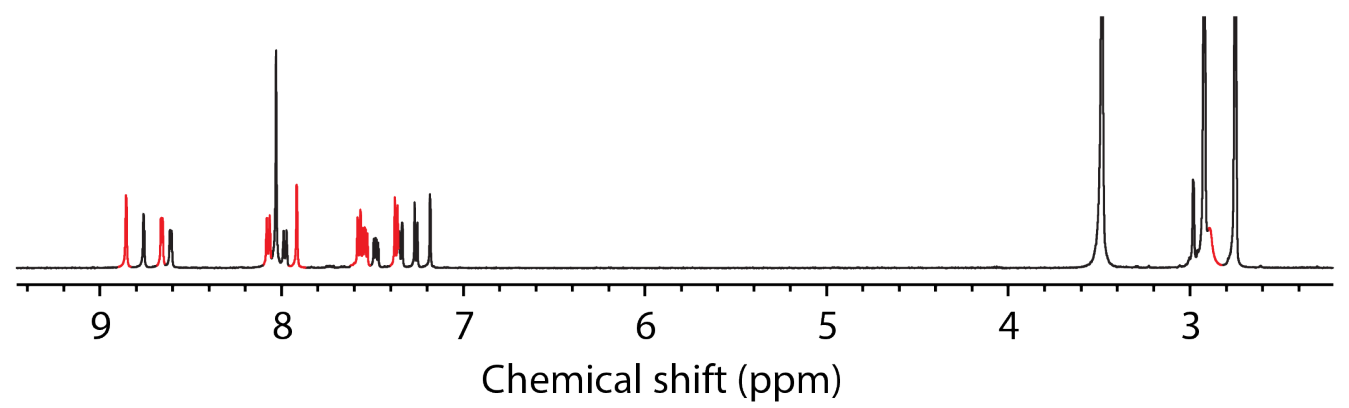

Figure S4. ${ }^{1} \mathrm{H}$ NMR spectrum $\left(500 \mathrm{MHz}, \mathrm{DMF}-d_{7}, 298 \mathrm{~K}\right)$ of trans-L and cis-L (integration ratio 62:38), highlighted in red color: trans-L. 


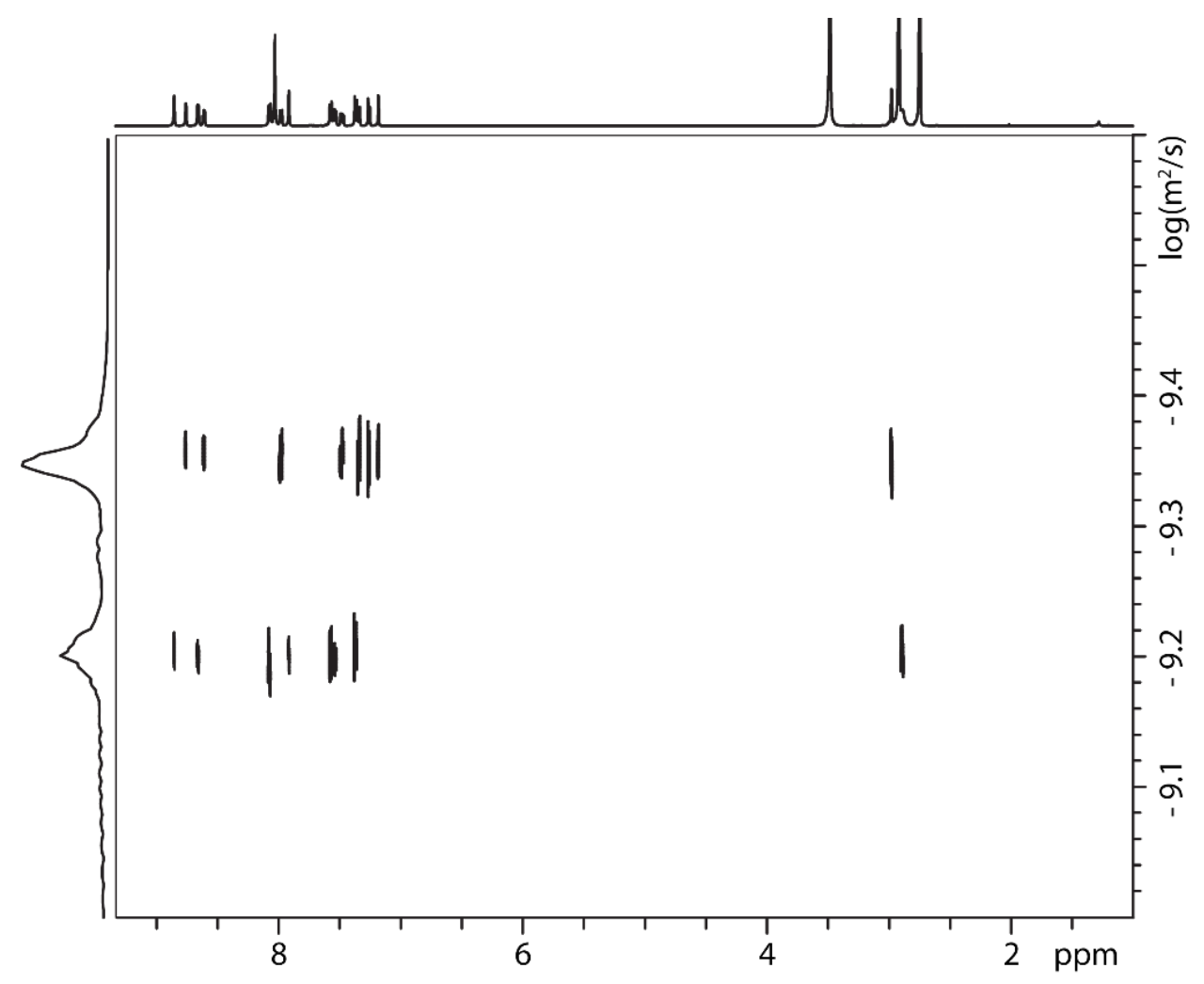

Figure S5. DOSY spectrum (500 MHz, DMF- $\left.d_{7}, 298 \mathrm{~K}\right)$ of a mixture of trans-L $(\mathrm{D}=6.22 \mathrm{x}$ $\left.10^{-10} \mathrm{~m}^{2} / \mathrm{s}\right)$ and $\boldsymbol{c i s}-\mathrm{L}\left(\mathrm{D}=4.35 \times 10^{-10} \mathrm{~m}^{2} / \mathrm{s}\right)$. 


\subsection{Synthesis of palladium(II) assemblies}

\subsubsection{Synthesis of cis-Cage, $\left[P d_{n}(\text { cis- } \mathbf{L})_{2 n}\right]\left(B F_{4}\right)_{2 n}$}

We use the term "cis-Cage" here to describe the equilibrated mixture containing the $\left[\operatorname{Pd}_{2}(\right.$ cisL) 4 cage as major component next to higher nuclear assemblies such as $\left[\operatorname{Pd}_{3}(\mathbf{c i s}-\mathbf{L})_{6}\right]$ and oligomeric species.

A $N, N^{\prime}$-dimethylformamide (DMF, $\left.450 \mu \mathrm{L}\right)$ solution of cis-L $(1.4 \mu \mathrm{mol}, 0.57 \mathrm{mg})$ was added to a DMF $(50 \mu \mathrm{L})$ solution of $\left[\mathrm{Pd}\left(\mathrm{CH}_{3} \mathrm{CN}\right)_{4}\right]\left(\mathrm{BF}_{4}\right)_{2}(0.7 \mu \mathrm{mol}, 0.3 \mathrm{mg})$ and the reaction mixture was heated for $5 \mathrm{~h}$ at $70{ }^{\circ} \mathrm{C} .{ }^{1} \mathrm{H} \mathrm{NMR}\left(500 \mathrm{MHz}, \mathrm{DMF}-d_{7}, 298 \mathrm{~K}\right) \delta 9.71,9.54,8.28,7.84,7.35$, $6.66,3.03$. DOSY-derived hydrodynamic radius of the major component $11.8 \AA$. ESI-TOF-MS $\mathrm{m} / \mathrm{z}=463.1050\left(\right.$ calcd for $\left.\left[\mathrm{PdL}_{2}\right]^{2+},\left[\mathrm{Pd}_{2} \mathrm{~L}_{4}\right]^{4+},\left[\mathrm{Pd}_{3} \mathrm{~L}_{6}\right]^{6+}, 463.1043\right), 647.1404$ (calcd for $\left.\left[\mathrm{Pd}_{2} \mathrm{~L}_{4}+\left(\mathrm{BF}_{4}\right)\right]^{3+}, 647.1421\right), 738.9091$ (calcd for $\left.\left[\mathrm{Pd}_{3} \mathrm{~L}_{6}+2\left(\mathrm{BF}_{4}\right)\right]^{4+}, 738.9106\right), 1013.2120$ (calcd for $\left.\left[\mathrm{PdL}_{2}+\left(\mathrm{BF}_{4}\right)\right]^{+},\left[\mathrm{Pd}_{2} \mathrm{~L}_{4}+2\left(\mathrm{BF}_{4}\right)\right]^{2+},\left[\mathrm{Pd}_{3} \mathrm{~L}_{6}+3\left(\mathrm{BF}_{4}\right)\right]^{3+}, 1013.2152\right)$.

\subsubsection{Synthesis of cis-Ring, $\left[\mathrm{Pd}_{2} \mathrm{Cl}_{4}(\text { cis- } \boldsymbol{L})_{2}\right]$}

A DMF solution $(2 \mathrm{~mL})$ of $\mathrm{PdCl}_{2}\left(\mathrm{CH}_{3} \mathrm{CN}\right)_{2}(0.01 \mathrm{mmol}, 2.6 \mathrm{mg})$ was slowly added to a dichloromethane solution $(3 \mathrm{~mL})$ of cis-L $(0.01 \mathrm{mmol}, 4.1 \mathrm{mg})$. After 2 days, yellow crystals were obtained from the solution. ${ }^{1} \mathrm{H}$ NMR $\left(500 \mathrm{MHz}, \mathrm{DMF}-d_{7}, 298 \mathrm{~K}\right) \delta 9.00\left(\mathrm{~d}, 2 \mathrm{H},{ }^{4} J=1.8\right.$ $\mathrm{Hz}), 8.98\left(\mathrm{~d}, 2 \mathrm{H},{ }^{4} \mathrm{~J}=1.9 \mathrm{~Hz}\right), 8.85\left(\mathrm{dd}, 4 \mathrm{H},{ }^{3} \mathrm{~J}=5,8 \mathrm{~Hz},{ }^{4} \mathrm{~J}=1.5 \mathrm{~Hz}\right), 8,2(\mathrm{~m}, 4 \mathrm{H}), 7.67$ (dd, $\left.4 \mathrm{H},{ }^{3} \mathrm{~J}=7.9 \mathrm{~Hz},{ }^{3} \mathrm{~J}=6.0 \mathrm{~Hz}\right), 7.37(\mathrm{~m}, 4 \mathrm{H}), 7.27(\mathrm{~m}, 4 \mathrm{H}), 2.98\left(\mathrm{~m}, \mathrm{C}_{2} \mathrm{H}_{4}\right)$. The NMR signals, especially protons $\mathrm{H}_{\mathrm{a}}$ and $\mathrm{H}_{\mathrm{d}}$, shows splitting, ascribed to the possible presence of two isomers, transoid and cisoid rings, as evidenced in section 5.1

\subsubsection{Synthesis of trans-Cage, $\left[P d_{2}(\text { trans- } L)_{4}\right]\left(B F_{4}\right)_{4}$}

A DMF solution $(450 \mu \mathrm{L})$ of cis-L $(1.4 \mu \mathrm{mol}, 0.57 \mathrm{mg})$ was irradiated by a $385 \mathrm{~nm}$ LED lamp for 10 minutes. In a dark room, $\left[\mathrm{Pd}\left(\mathrm{CH}_{3} \mathrm{CN}\right)_{4}\right]\left(\mathrm{BF}_{4}\right)_{2}(0.7 \mu \mathrm{mol}, 0.3 \mathrm{mg})$, dissolved in $50 \mu \mathrm{L}$ DMF, was added to the solution. ${ }^{1} \mathrm{H}$ NMR $\left(500 \mathrm{MHz}, \mathrm{DMF}-d_{7}, 298 \mathrm{~K}\right) \delta 9.80(\mathrm{~s}, 2 \mathrm{H}), 9.63(\mathrm{br}$, 2H), $8.40\left(\mathrm{~d},{ }^{3} J=7.8 \mathrm{~Hz}, 2 \mathrm{H}\right), 7.94\left(\mathrm{t},{ }^{3} J=6.7 \mathrm{~Hz}, 2 \mathrm{H}\right), 7.75(\mathrm{br}, 2 \mathrm{H}), 7.38\left(\mathrm{~d},{ }^{3} J=7.1 \mathrm{~Hz}, 2 \mathrm{H}\right)$, $7.37\left(\mathrm{~d},{ }^{3} \mathrm{~J}=7.9 \mathrm{~Hz}, 2 \mathrm{H}\right), 2.95\left(\mathrm{br}, 4 \mathrm{H}, \mathrm{C}_{2} \mathrm{H}_{4}\right.$ ). Diffusion coefficient $2.21 \times 10^{-10} \mathrm{~m}^{2} / \mathrm{s}$, DOSYderived hydrodynamic radius $11.5 \AA$. ESI-TOF-MS m/z $=463.6042$ (calcd for $\left[\mathrm{Pd}_{2} \mathrm{~L}_{4}\right]^{4+}$, 463.6055), 647.1386 (calcd for $\left[\mathrm{Pd}_{2} \mathrm{~L}_{4}+\left(\mathrm{BF}_{4}\right)\right]^{3+}, 647.1421$ ), 1013.2093 (calcd for $\left.\left[\mathrm{Pd}_{2} \mathrm{~L}_{4}+2\left(\mathrm{BF}_{4}\right)\right]^{2+}, 1013.2152\right)$. 


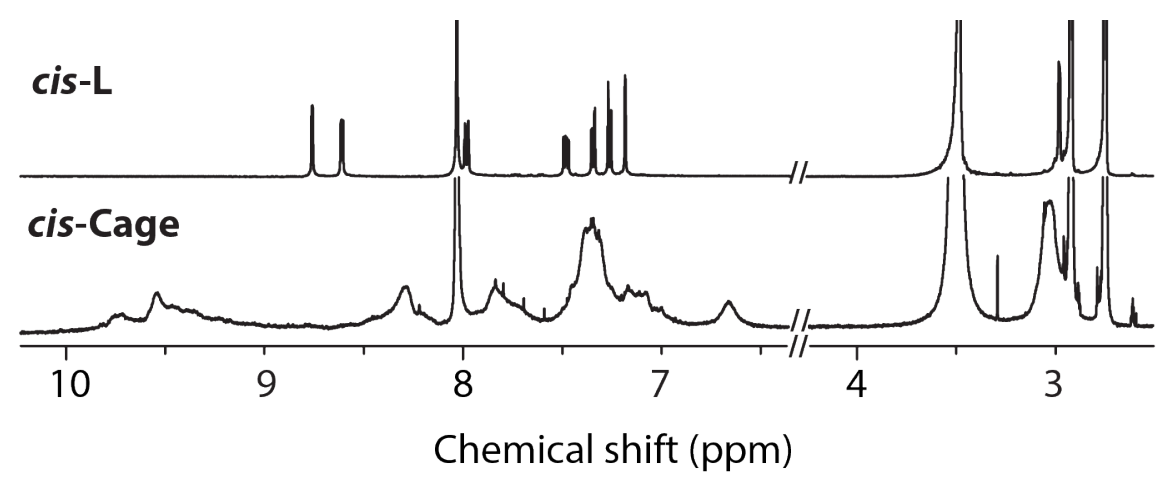

Figure S6. ${ }^{1} \mathrm{H}$ NMR spectrum (500 MHz, DMF- $d_{7}, 298 \mathrm{~K}$ ) for cis-L and cis-Cage.

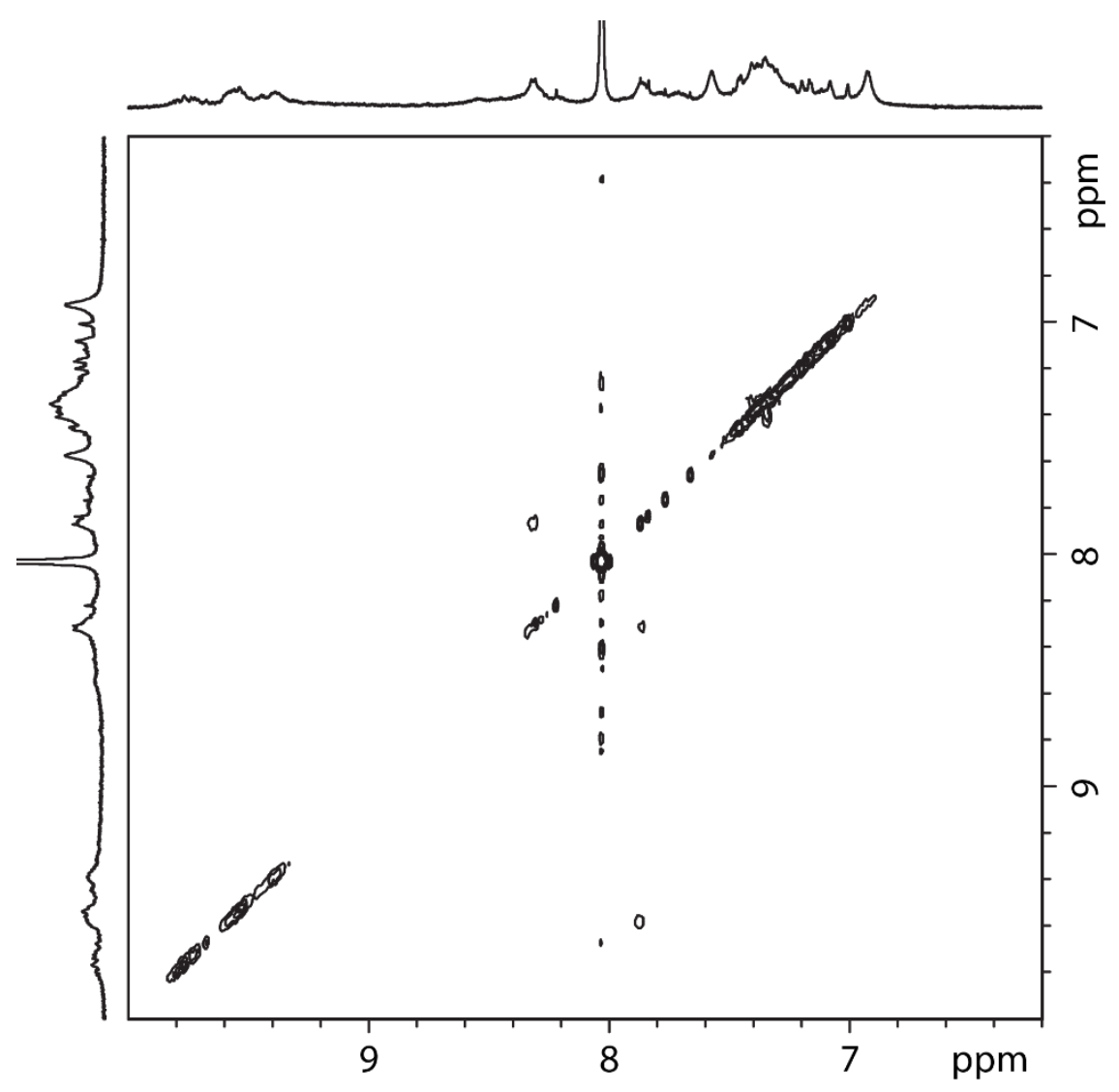

Figure S7. COSY spectra (500 MHz, DMF-d7, 298 K) for cis-Cage. 


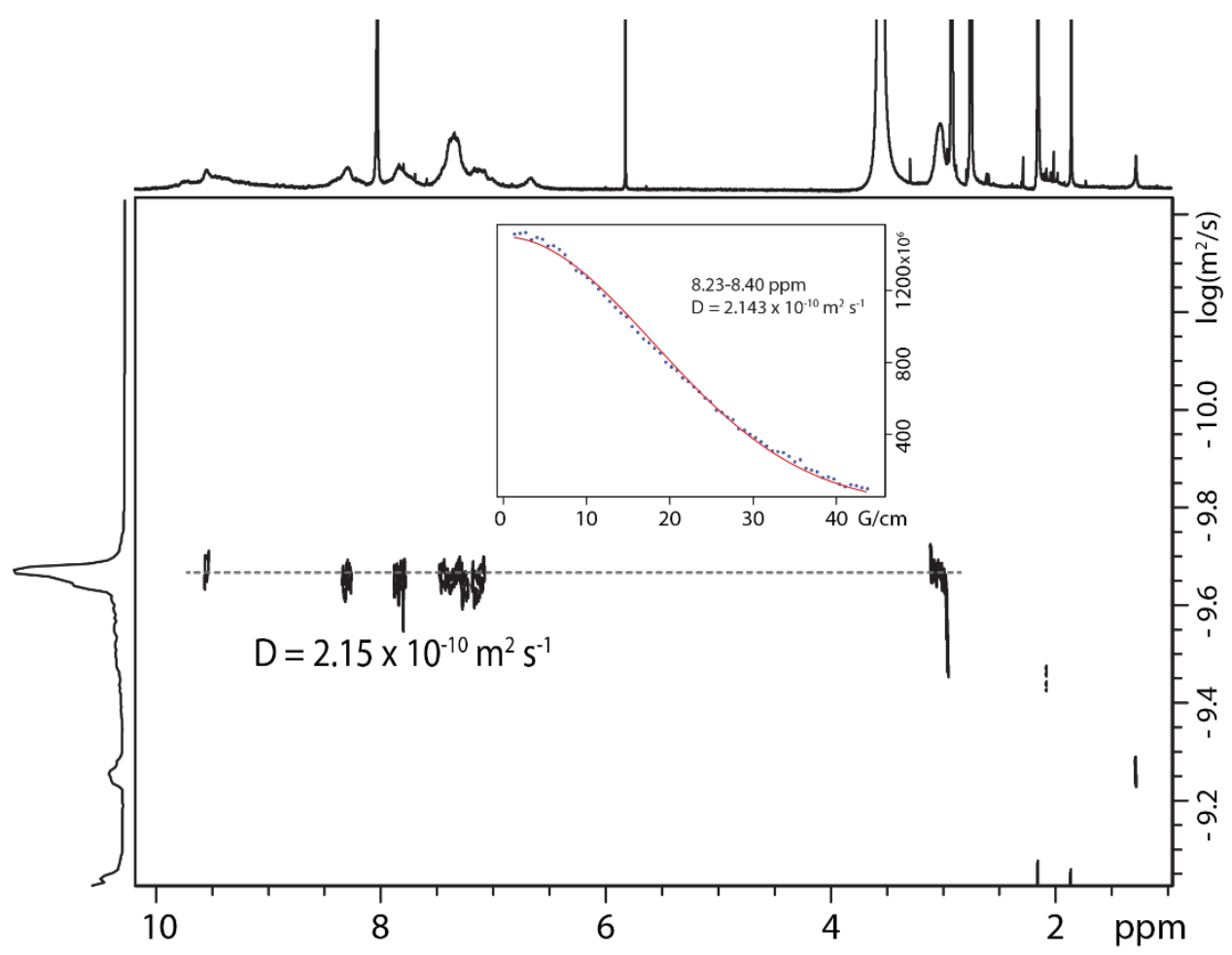

Figure S8. DOSY spectrum ( $\left.500 \mathrm{MHz}, \mathrm{DMF}-d_{7}, 298 \mathrm{~K}\right)$ for the cis-Cage mixture $(\mathrm{D}=2.15 \mathrm{x}$ $10^{-10} \mathrm{~m}^{2} / \mathrm{s}$ ), relaxation fitting for the area between 8.23 and $8.40 \mathrm{ppm}$ shown in the inset.

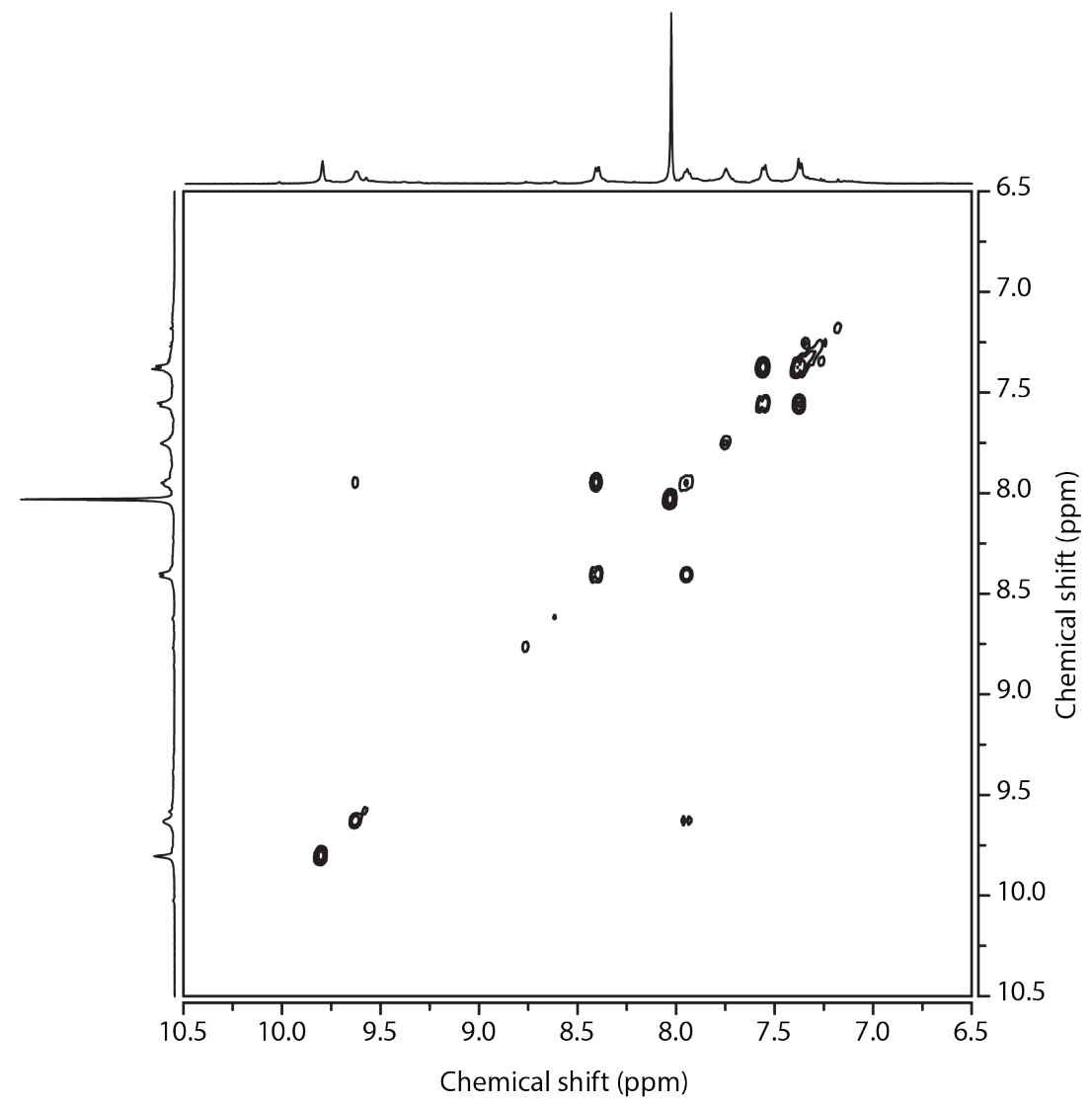

Figure S9. COSY spectra (500 MHz, DMF- $\left.d_{7}, 298 \mathrm{~K}\right)$ for trans-Cage. 


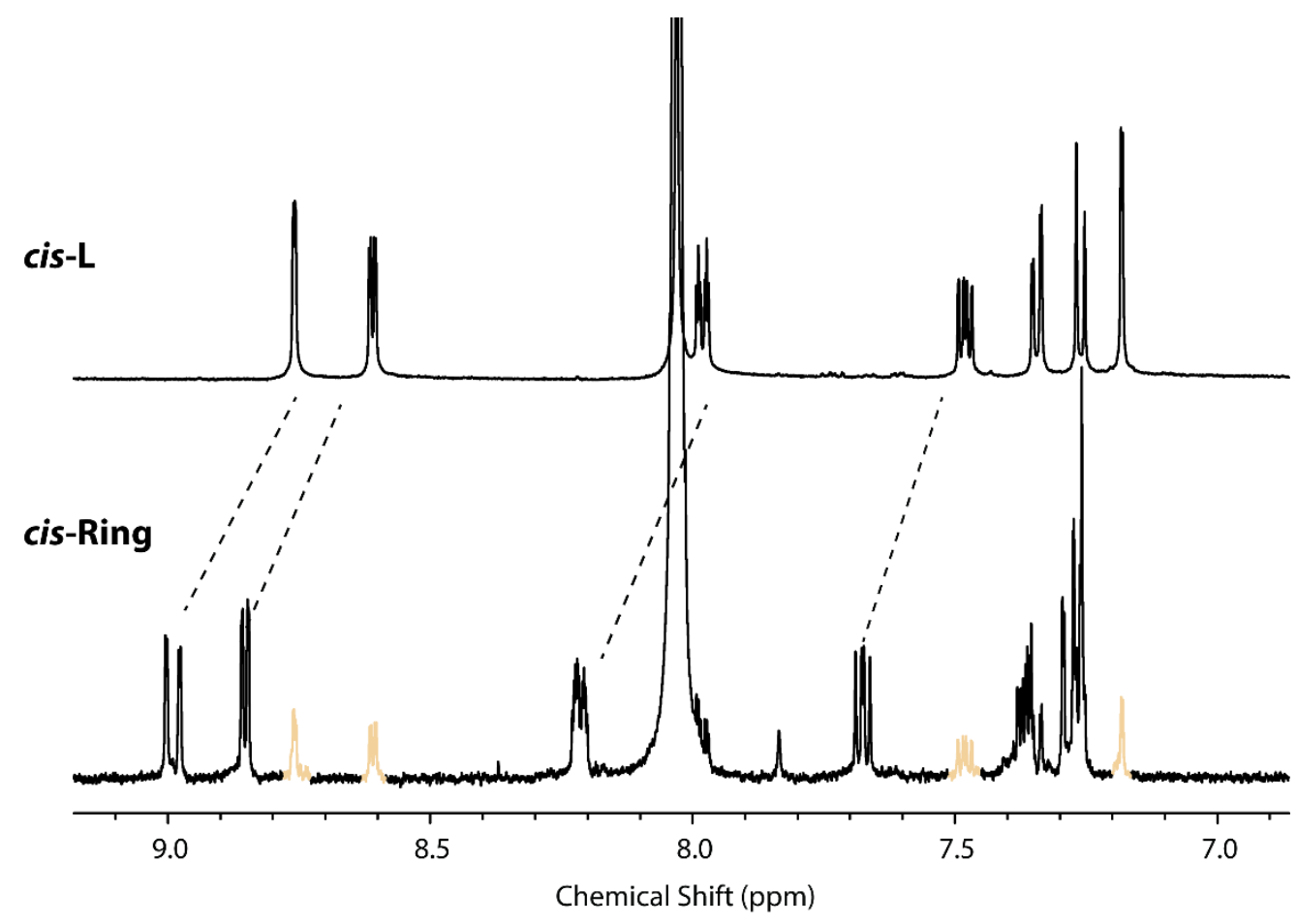

Figure S10. ${ }^{1} \mathrm{H}$ NMR spectrum $\left(500 \mathrm{MHz}, \mathrm{DMF}-d_{7}, 298 \mathrm{~K}\right)$ for cis-L and cis-Ring, residual L signals highlighted in beige.

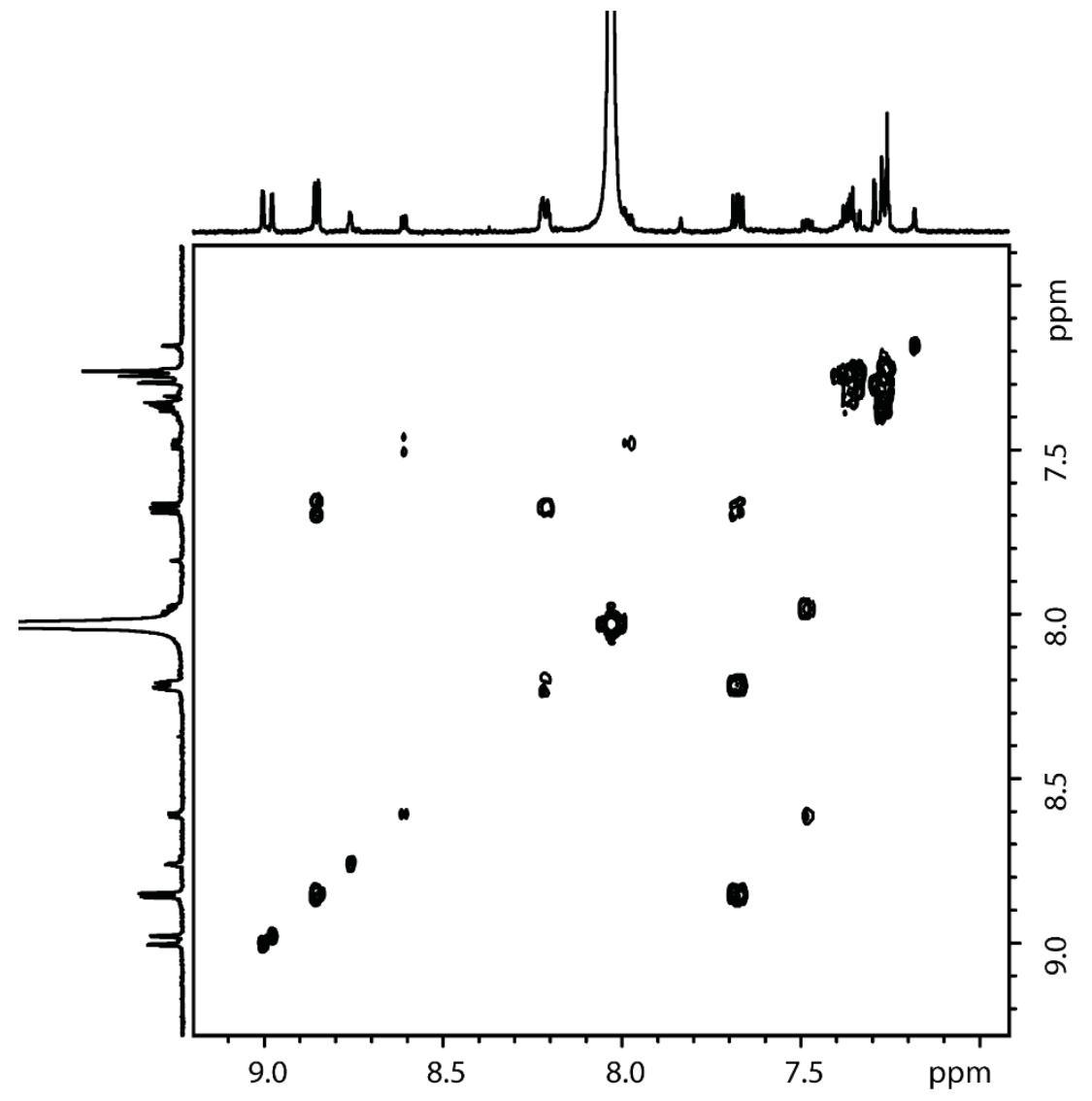

Figure S11. COSY spectra (500 MHz, DMF-d7, $298 \mathrm{~K}$ ) for cis-Ring. 


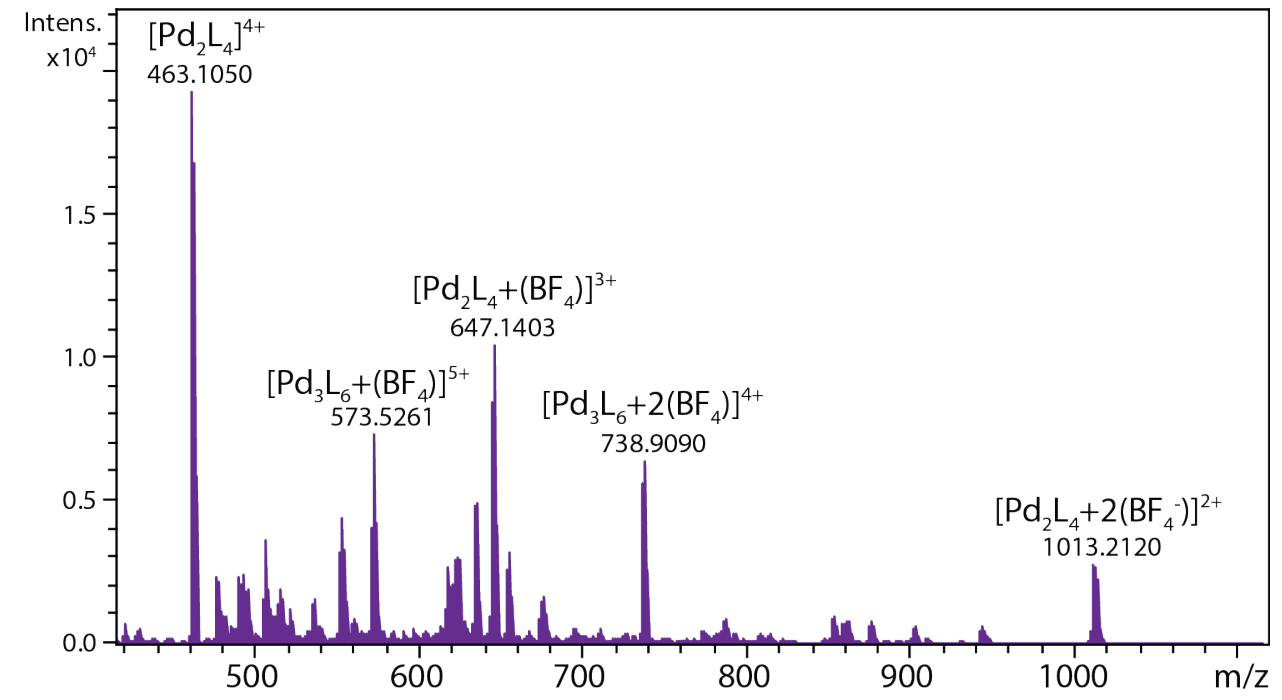

(a) Measured m/z 1013.2120

(b) Measured m/z 738.9090
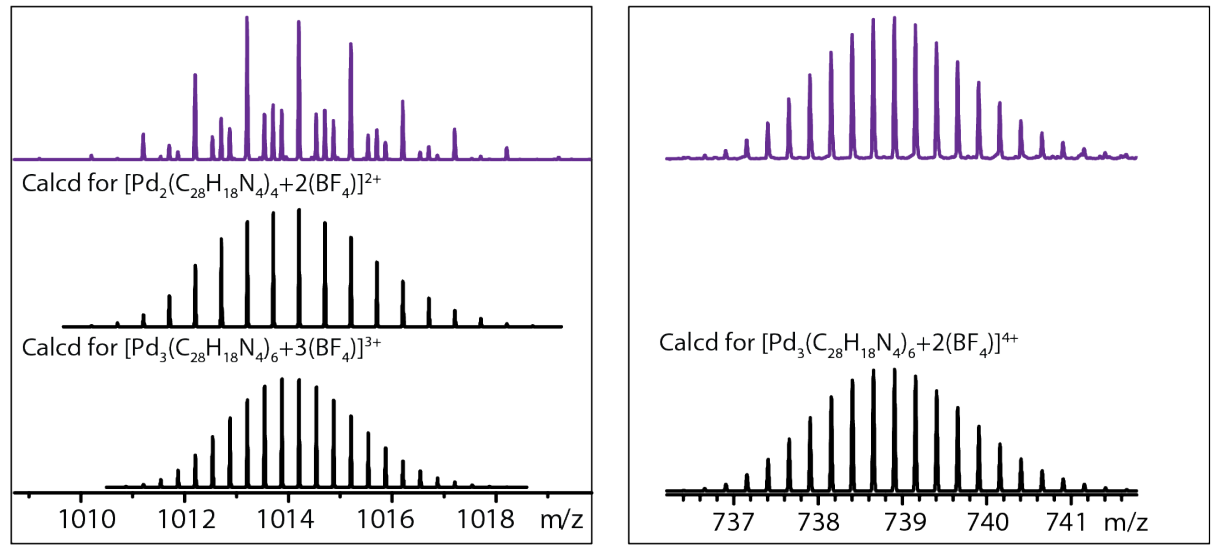

(c) Measured $\mathrm{m} / \mathrm{z} 647.1403$

(d) Measured m/z 573.5261
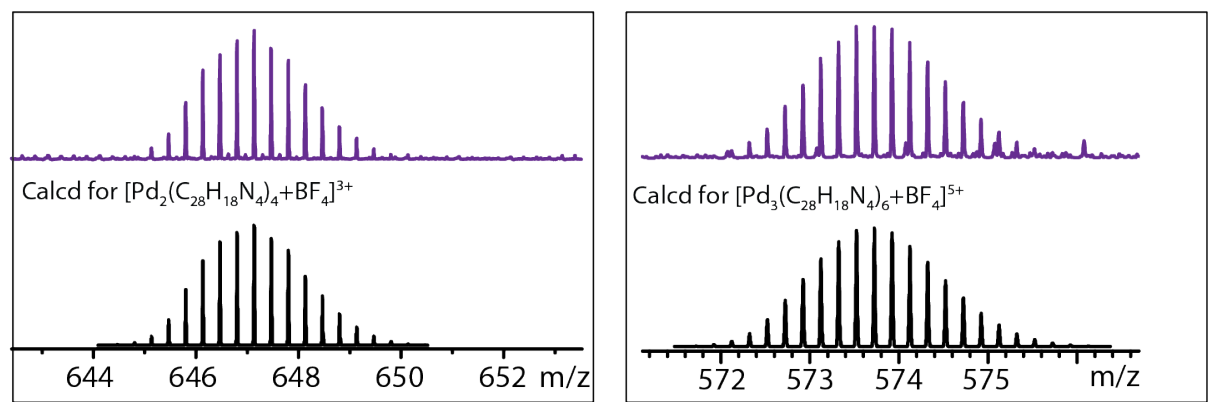

Figure S12. ESI-MS spectrum of cis-Cage with measured and calculated isotopic patterns of a) overlap of $\left[\mathrm{Pd}_{2} \text { cis- } \mathrm{L}_{4}+2\left(\mathrm{BF}_{4}\right)\right]^{2+}$ and $\left[\mathrm{Pd}_{3} \text { cis- } \mathrm{L}_{6}+3\left(\mathrm{BF}_{4}\right)\right]^{3+}$; b) $\left[\mathrm{Pd}_{3} \text { cis- }-\mathrm{L}_{6}+2\left(\mathrm{BF}_{4}\right)\right]^{4+}$; c) $\left.\left[\mathrm{Pd}_{2} \text { cis- } \mathbf{L}_{4}+\mathrm{BF}_{4}\right]^{3+} ; \mathrm{d}\right)\left[\mathrm{Pd}_{3} \text { cis- } \mathbf{L}_{6}+\mathrm{BF}_{4}\right]^{5+}$. 


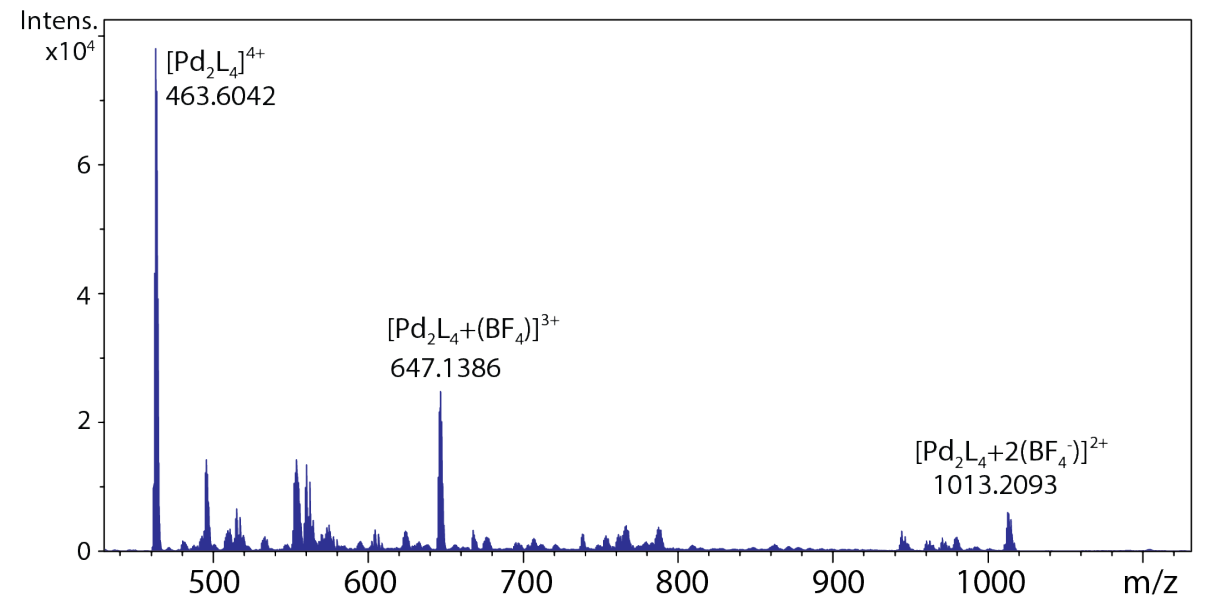

(a) Measured m/z 1013.2093

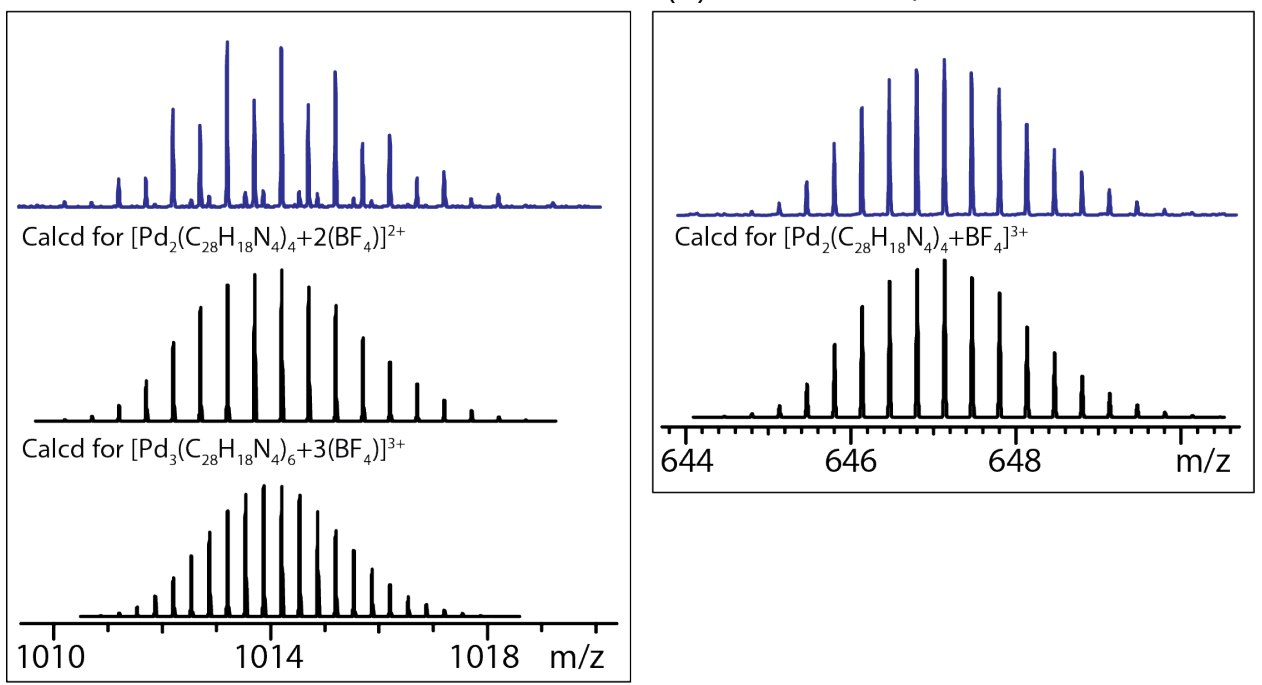

Figure S13. ESI-MS spectrum of trans-Cage with measured and calculated isotopic patterns of a) overlap of $\left[\mathrm{Pd}_{2} \text { trans }-\mathrm{L}_{4}+2\left(\mathrm{BF}_{4}\right)\right]^{2+}$ and minor presence of $\left.\left[\mathrm{Pd}_{3} \text { trans }-\mathrm{L}_{6}+3\left(\mathrm{BF}_{4}\right)\right]^{3+} ; \mathrm{b}\right)$ $\left[\mathrm{Pd}_{2} \text { trans }-\mathrm{L}_{4}+\left(\mathrm{BF}_{4}\right)\right]^{3+}$. 
(a) cis-L

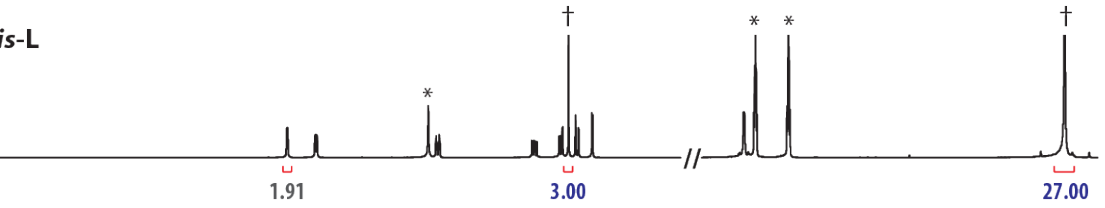

(b) cis-Cage

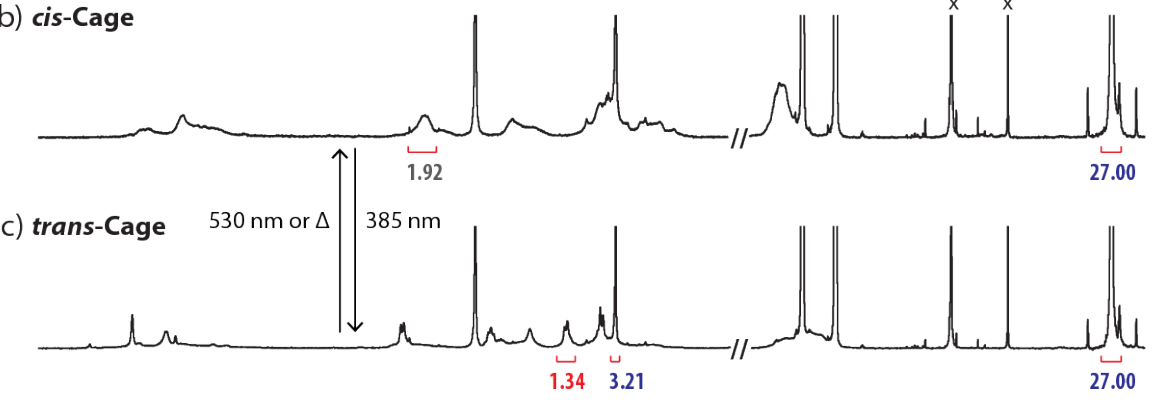

(d) trans-L

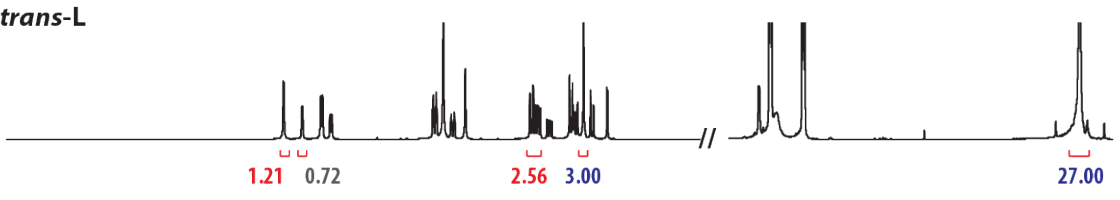

(e) trans-L + Pd" (2 eq : 0.2 eq)

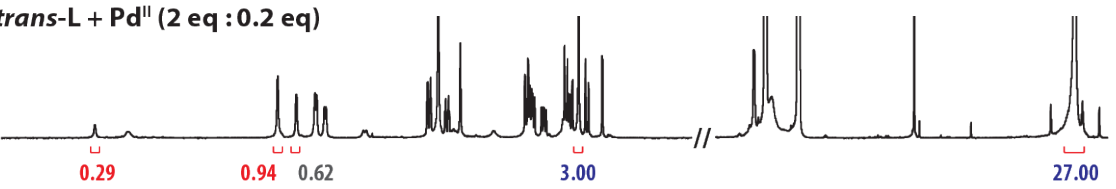

(f) trans-L + Pd" (2 eq : 0.4 eq)

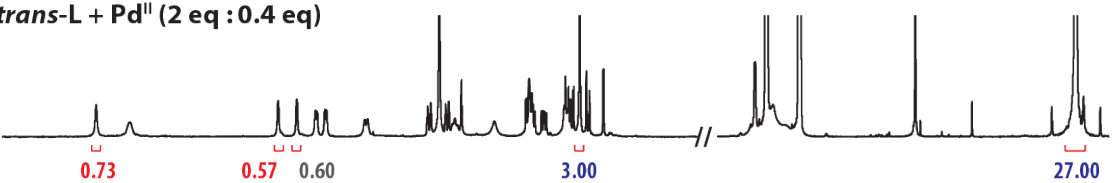

(g) trans-L + Pd" (2 eq : 0.6 eq)

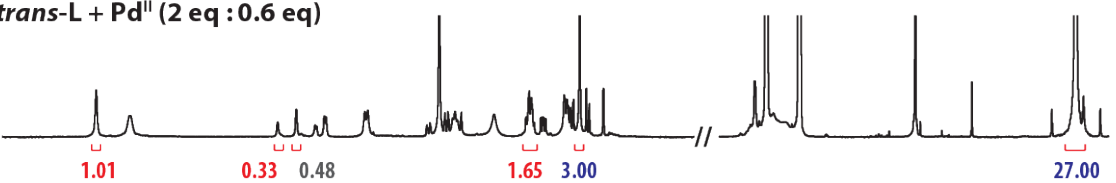

(h) trans-L + Pd" (2 eq : 0.8 eq)

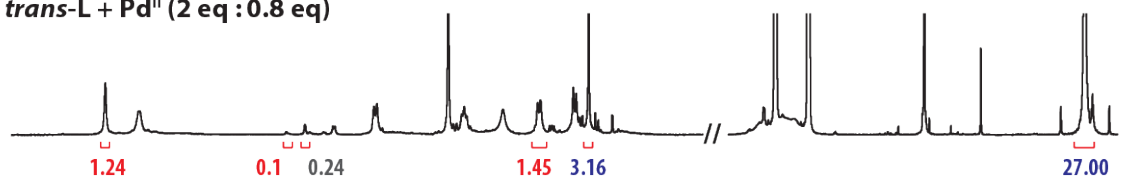

(i) trans-L + Pd" (2 eq : 1 eq)

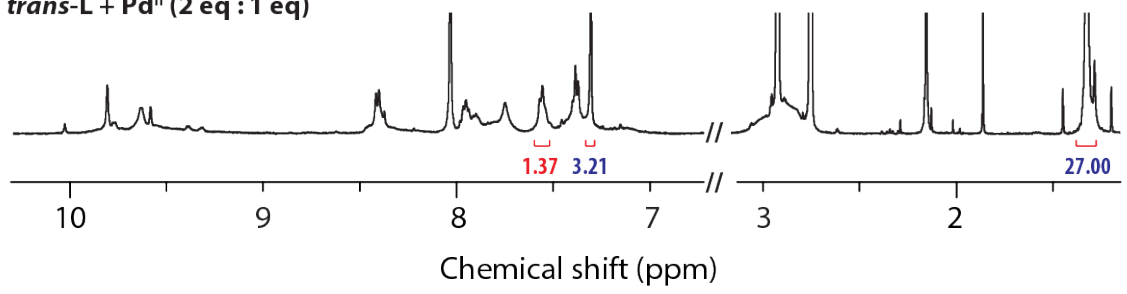

Figure S14. ${ }^{1} \mathrm{H}$ NMR (500 MHz, DMF- $\left.d_{7}, 298 \mathrm{~K}\right)$ showing trans-Cage formation with internal standard ( ${ }^{\dagger} 1,3,5$-tris-tert-butylbenzene (InRef), *solvent residue). All spectra were obtained from the same stock solution, signals for the pyridine protons of cis and trans-ligands are highlighted in red. (Integral color code: red for trans-isomers, gray for cis-isomers, blue for InRef) 
According to integral ratios, (a) molecular ratio cis-L : InRef $=0.96: 1$; (b) cis-Cage : InRef $=$ $0.96: 1, \rightarrow$ entire cis-L is consumed for cis-Cage formation; (c) $385 \mathrm{~nm}$ irradiation causes photoswitching of cis-Cage to trans-Cage, trans-C $:$ InRef $=0.67: 1, \rightarrow$ the yield for transCage is $69 \%$; (d) ratio cis-L : trans-L : InRef $=0.36: 0.61: 1,63 \%$ PSS; (e)-(i) stepwise addition of palladium(II) precursor, (e) cis-L : trans-L : trans-Cage : InRef $=0.31: 0.47: 0.15$ : $1, \rightarrow$ the yield for trans-Cage is $16 \%$; (f) cis-L : trans-L : trans-Cage : InRef $=0.3: 0.28:$ $0.37: 1, \rightarrow$ the yield for trans-Cage is $38 \%$; $(\mathrm{g})$ cis-L : trans-L : trans-Cage $:$ InRef $=0.24:$ $0.15: 0.51: 1, \rightarrow$ the yield for trans-Cage is $55 \%$; (h) cis-L $:$ trans-L $:$ trans-Cage $:$ InRef $=$ $0.12: 0.05: 0.62: 1, \rightarrow$ the yield for trans-Cage is $65 \%$; (i) trans-Cage $:$ InRef $=0.68: 1, \rightarrow$ the yield for trans-Cage is $70 \%$. 


\section{Photoswitching properties}

\subsection{Determination of the photostationary state of L (PSS@ 385 nm)}

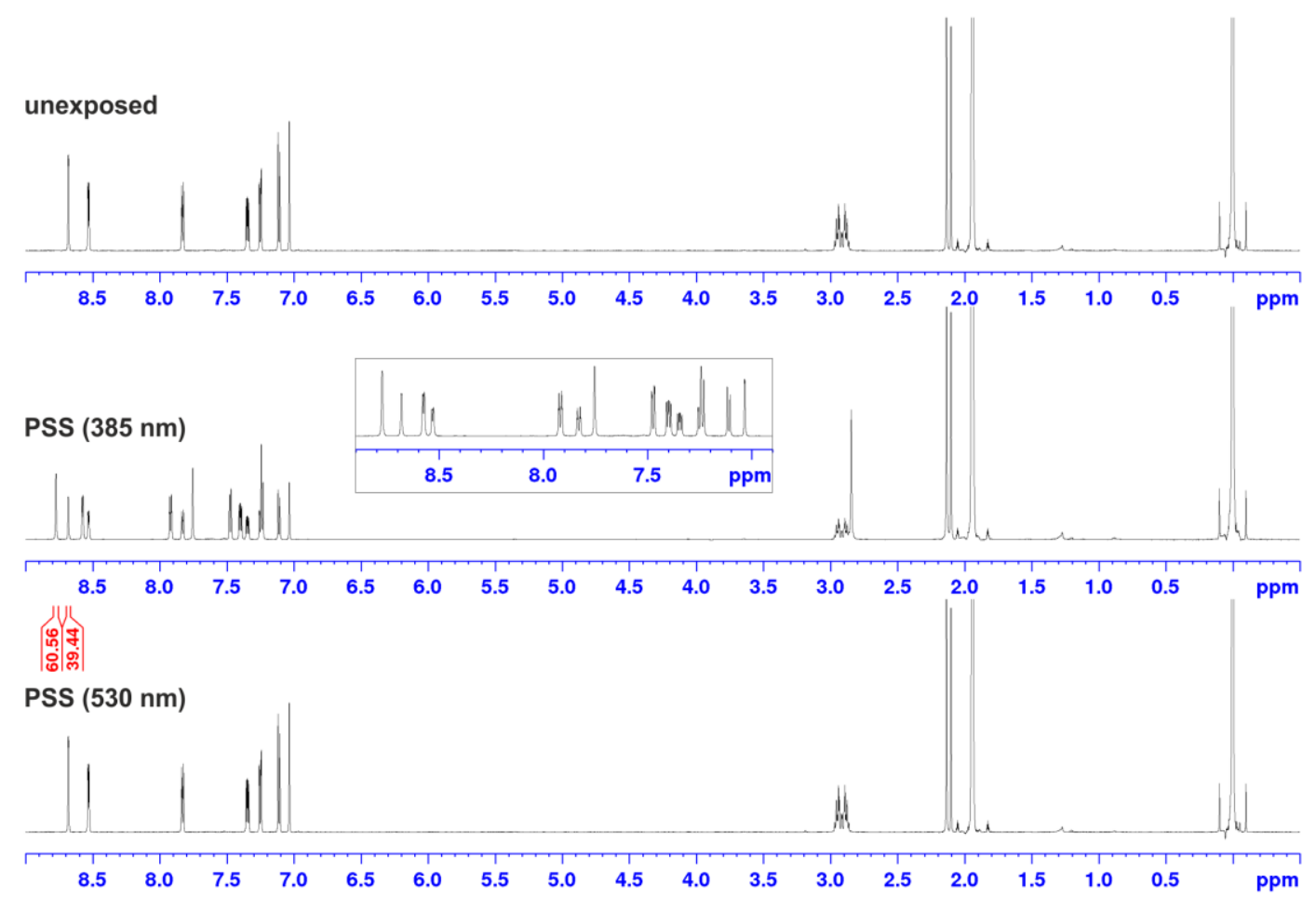

Figure S15. Measurement of the photostationary state (PSS @ $385 \mathrm{~nm}$ ) by ${ }^{1} \mathrm{H}-\mathrm{NMR}$ spectroscopy in acetonitrile- $d_{3}$ at $300 \mathrm{~K}$. The sample was first measured without irradiation, then the compound was irradiated twice at $385 \mathrm{~nm}$ for $5 \mathrm{~min}$. At the end, the sample was irradiated at $530 \mathrm{~nm}$ for $5 \mathrm{~min}$. The irradiation experiment took place in a NMR tube $(1 \mathrm{mg}$ of substance, $500 \mu \mathrm{L}$ of acetonitrile- $\left.d_{3}\right)$. 


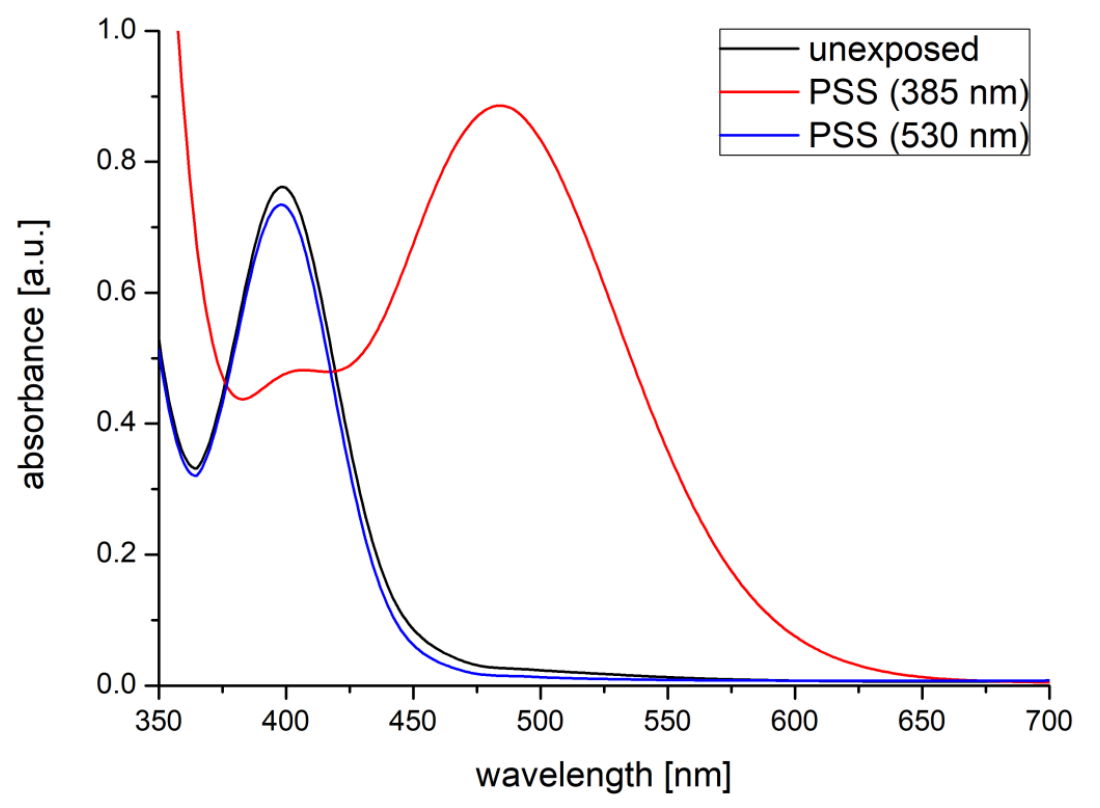

Figure S16. UV-vis spectra of the ligand. black line: unexposed (cis-L), red line: PSS (385 $\mathrm{nm})$ and blue line $(530 \mathrm{~nm})$. The $\mathrm{UV}$-vis spectra were measured in acetonitrile at $298 \mathrm{~K}$. Concentration: $1.52 \mathrm{mmol} / \mathrm{L}$. 
3.2. Thermal relaxation of meta-stable trans- $\mathrm{L}$ and trans-Cage to stable cis-forms

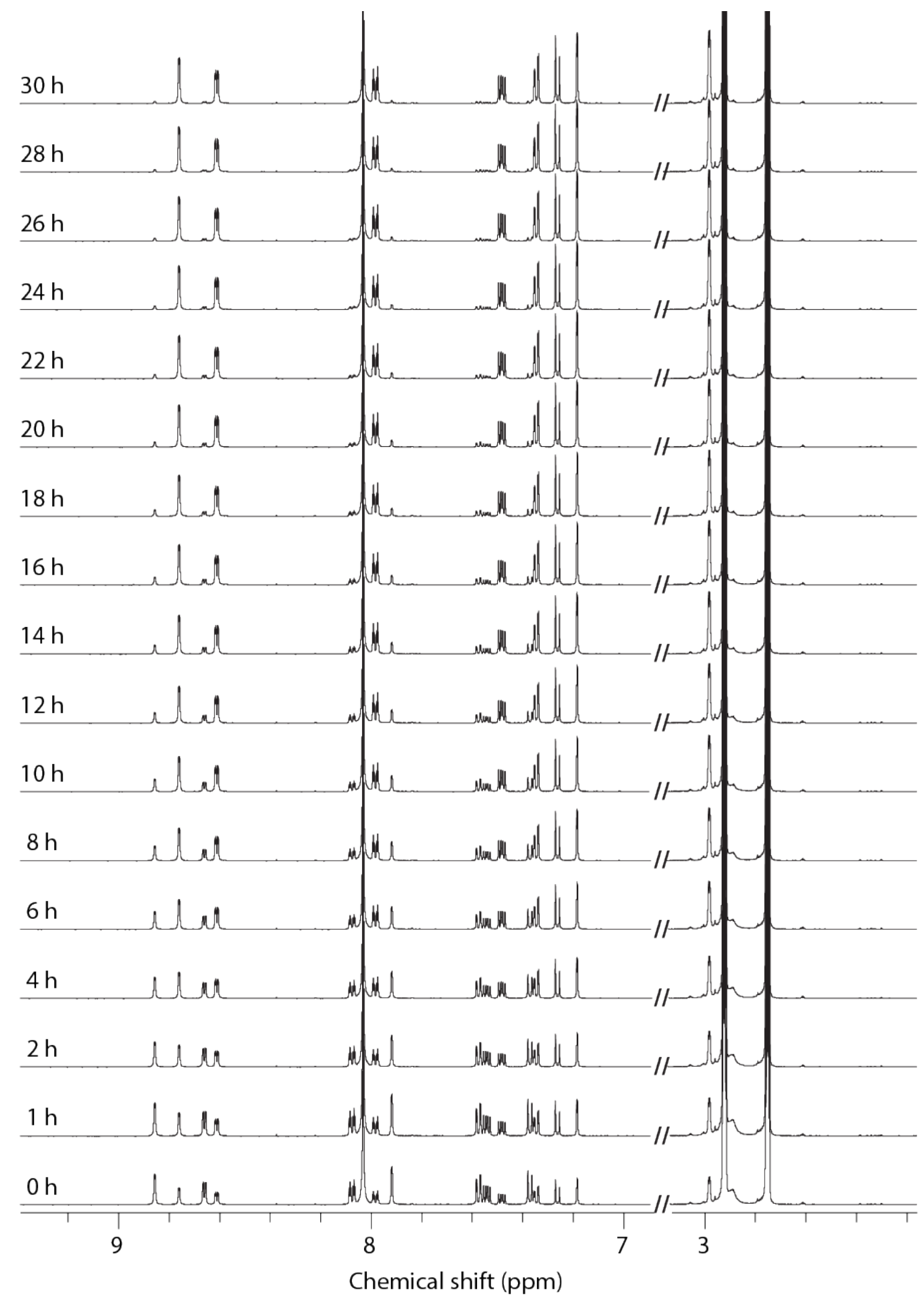

Figure S17. Time-dependent ${ }^{1} \mathrm{H}$ NMR monitoring ( $500 \mathrm{MHz}$, DMF- $d 7$, $298 \mathrm{~K}$ ) of the thermal relaxation of trans-L. 


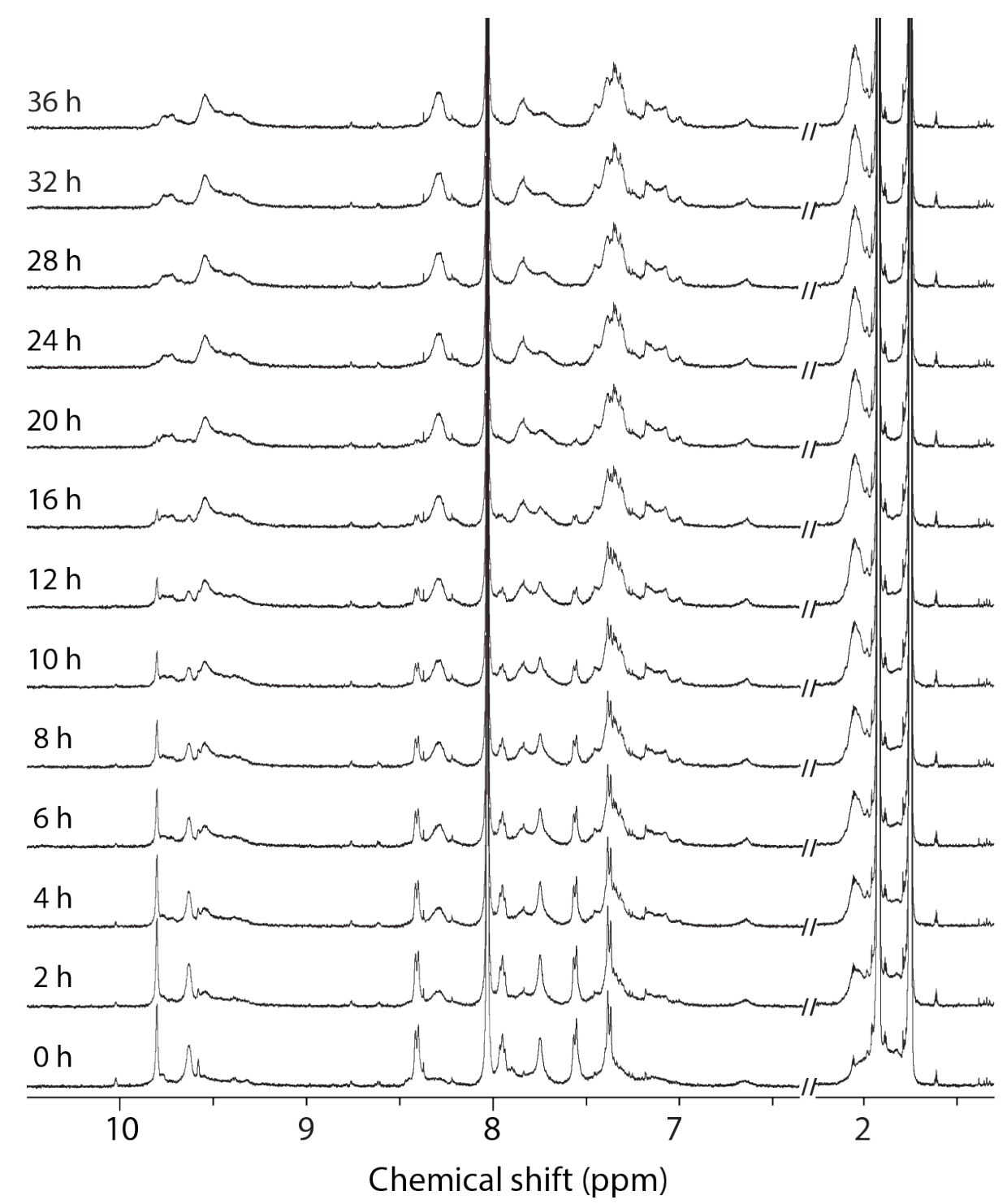

Figure S18. Time-dependent ${ }^{1} \mathrm{H}$ NMR monitoring (500 MHz, DMF- $d_{7}, 298 \mathrm{~K}$ ) of the thermal relaxation of trans-Cage. 


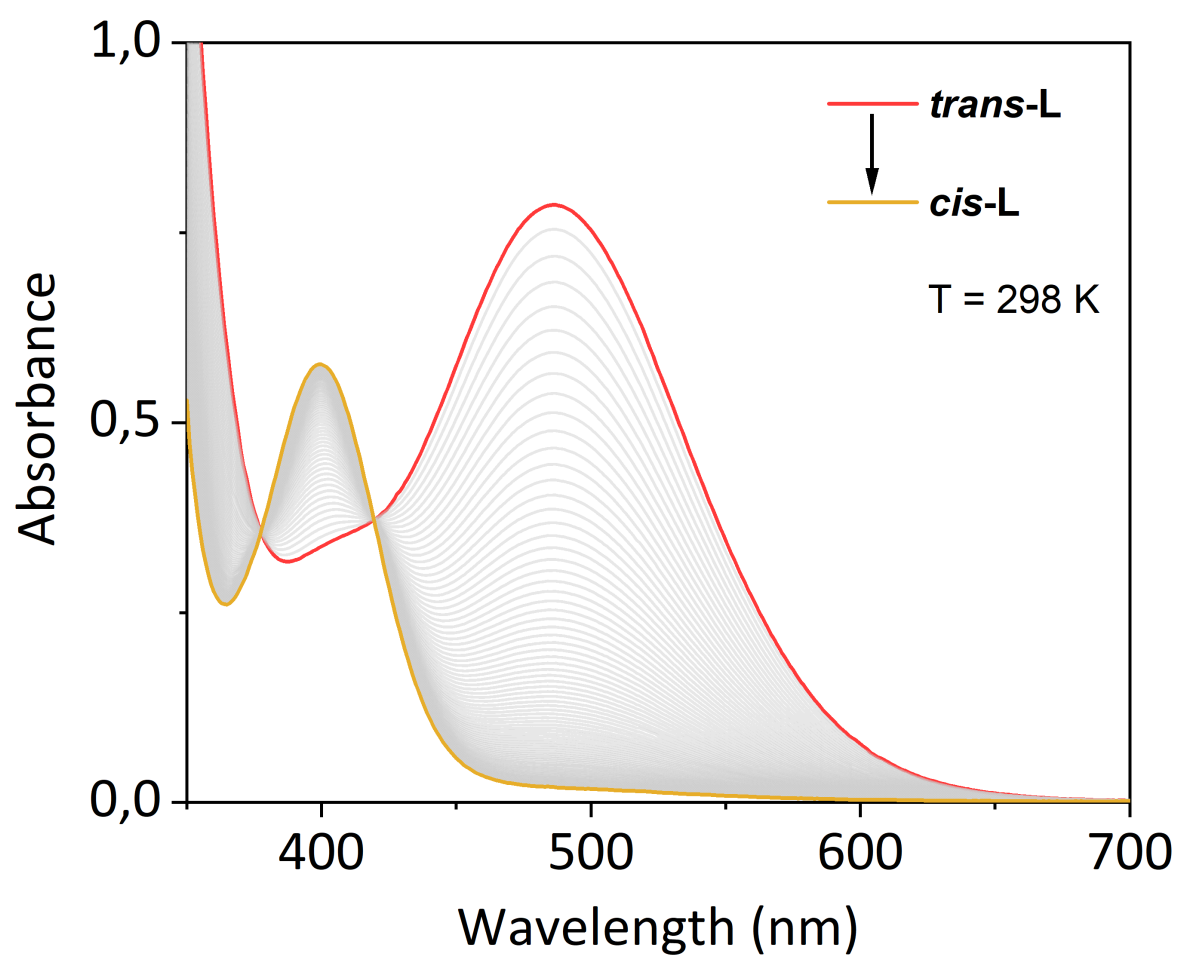

Figure S19. Time-dependent UV-Vis spectra at T $=298 \mathrm{~K}(1.12 \mathrm{mM}$ in DMF), for the thermal relaxation of trans-L.

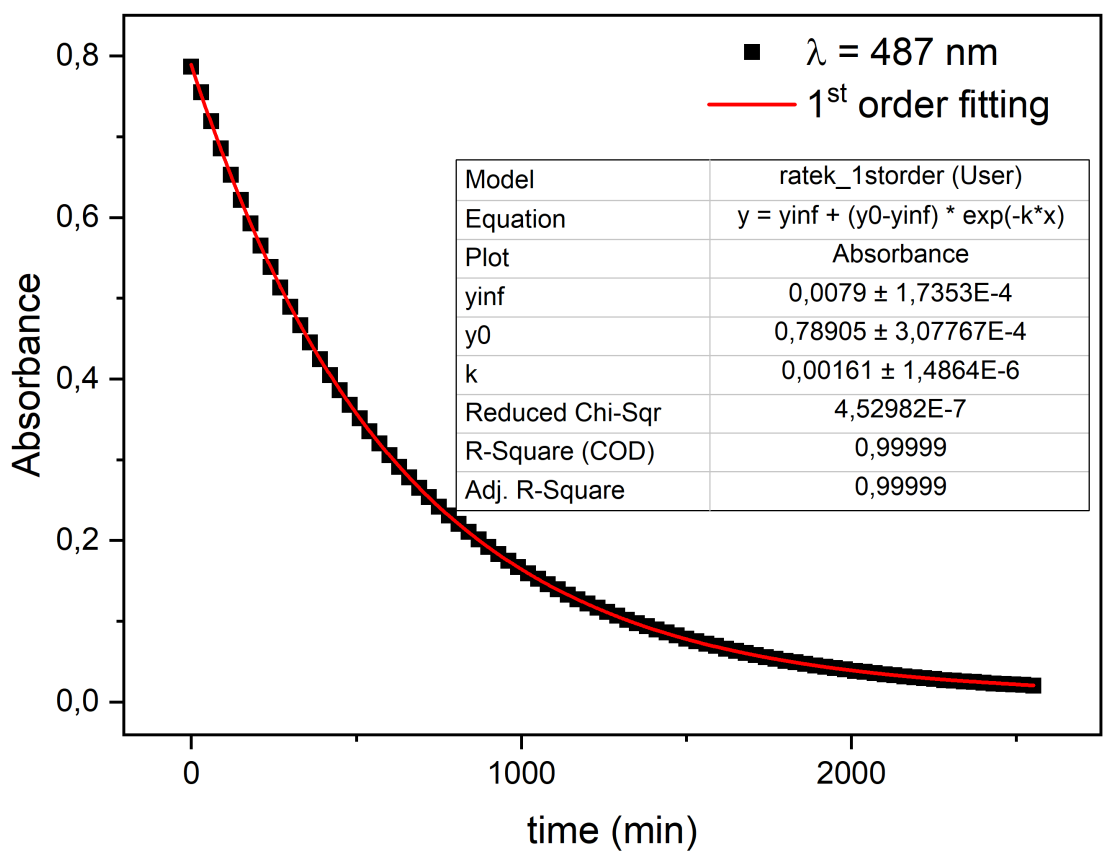

Figure S20. Absorbance decay of trans-L monitored at $\lambda=487 \mathrm{~nm}$ at $\mathrm{T}=298 \mathrm{~K}$ (black squares), and fitting following a $1^{\text {st }}$ order kinetics (red line). 


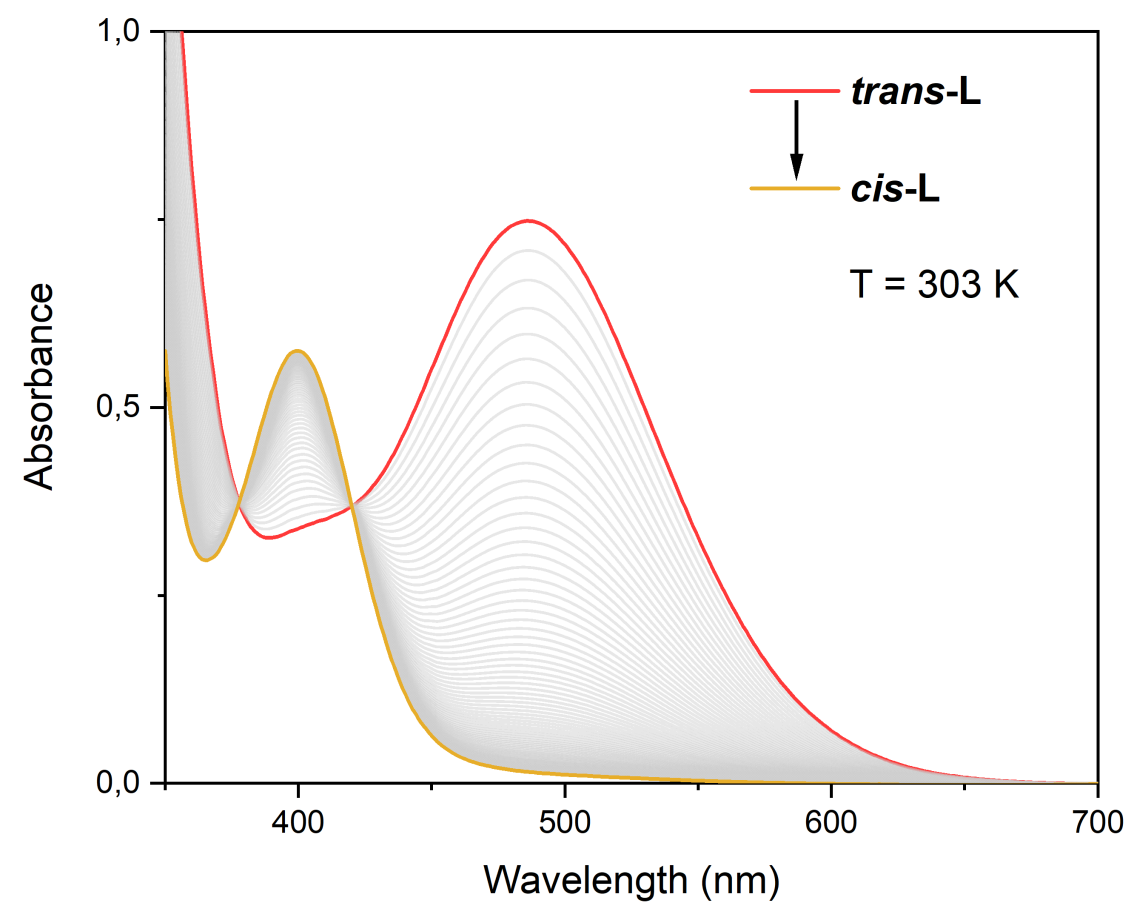

Figure S21. Time dependent UV-Vis spectra at $\mathrm{T}=303 \mathrm{~K}(1.12 \mathrm{mM}$ in DMF), for the thermal relaxation of trans-L.

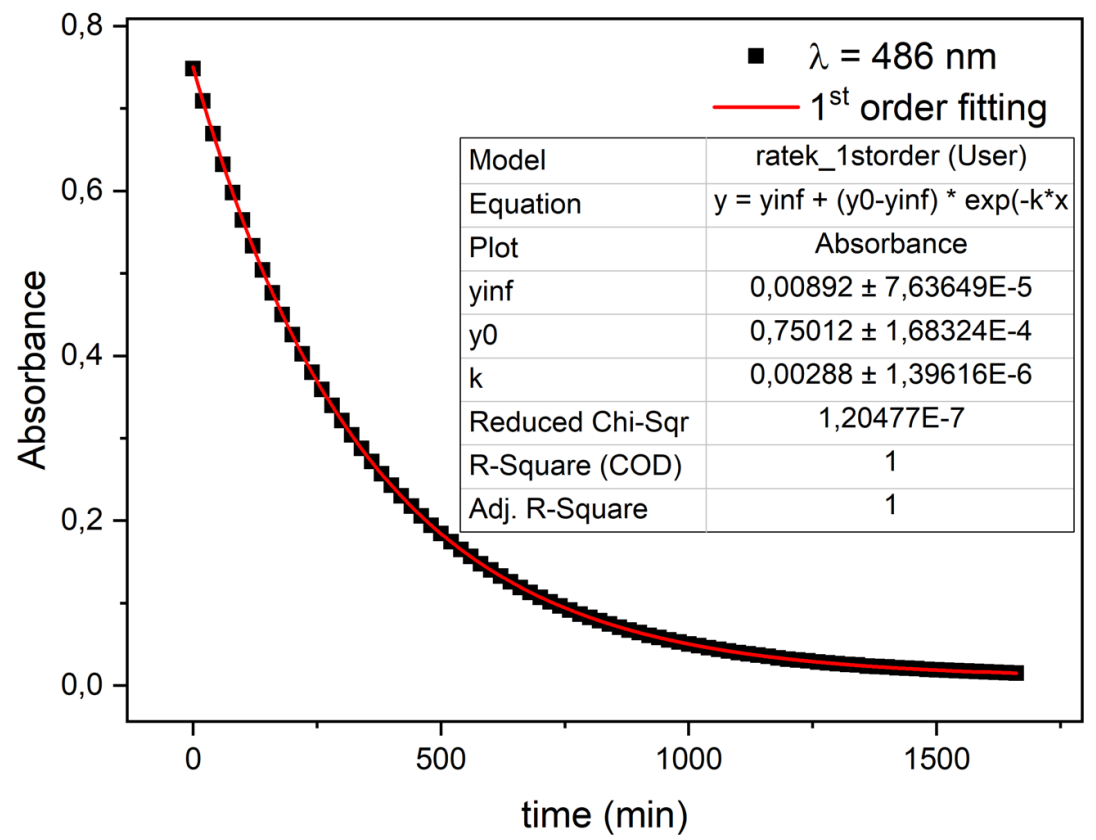

Figure S22. Absorbance decay of trans-L monitored at $\lambda=486 \mathrm{~nm}$ at $\mathrm{T}=303 \mathrm{~K}$ (black squares), and fitting following a $1^{\text {st }}$ order kinetics (red line). 


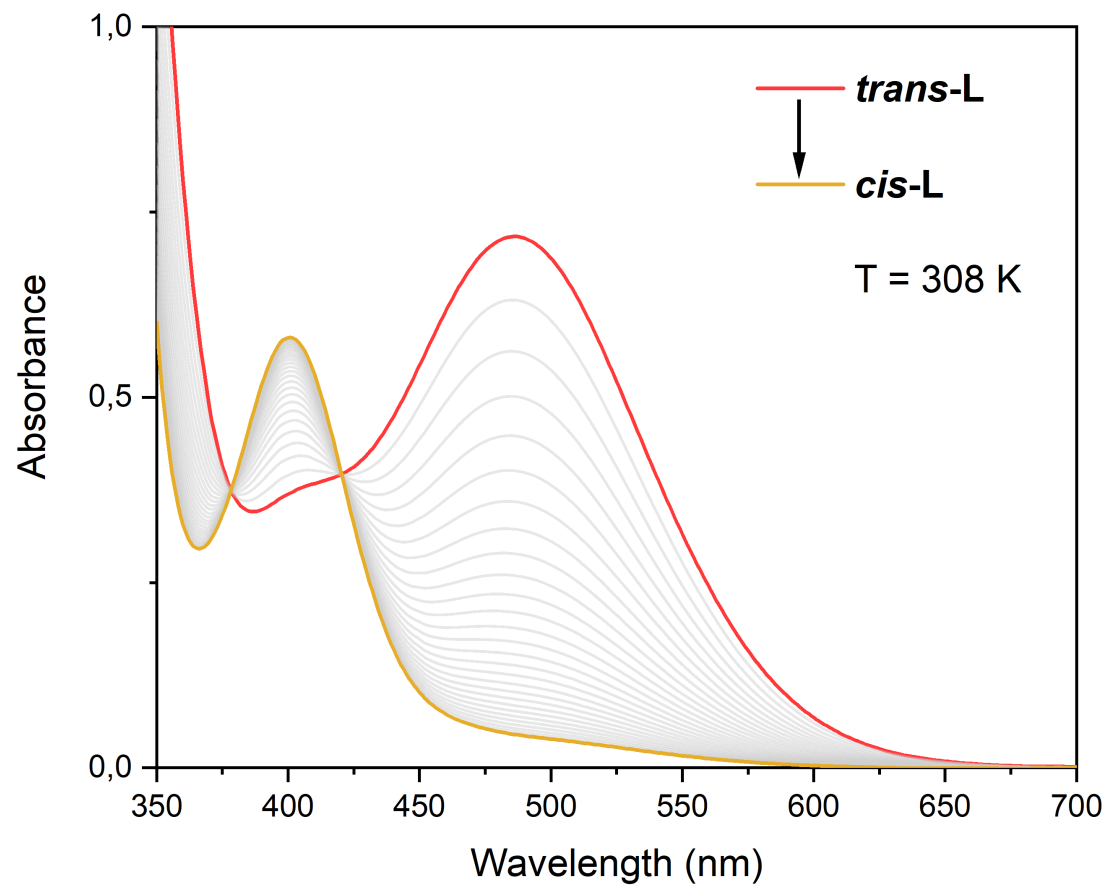

Figure S23. Time dependent UV-Vis spectra at $\mathrm{T}=308 \mathrm{~K}(1.12 \mathrm{mM}$ in DMF), for the thermal relaxation of trans-L.

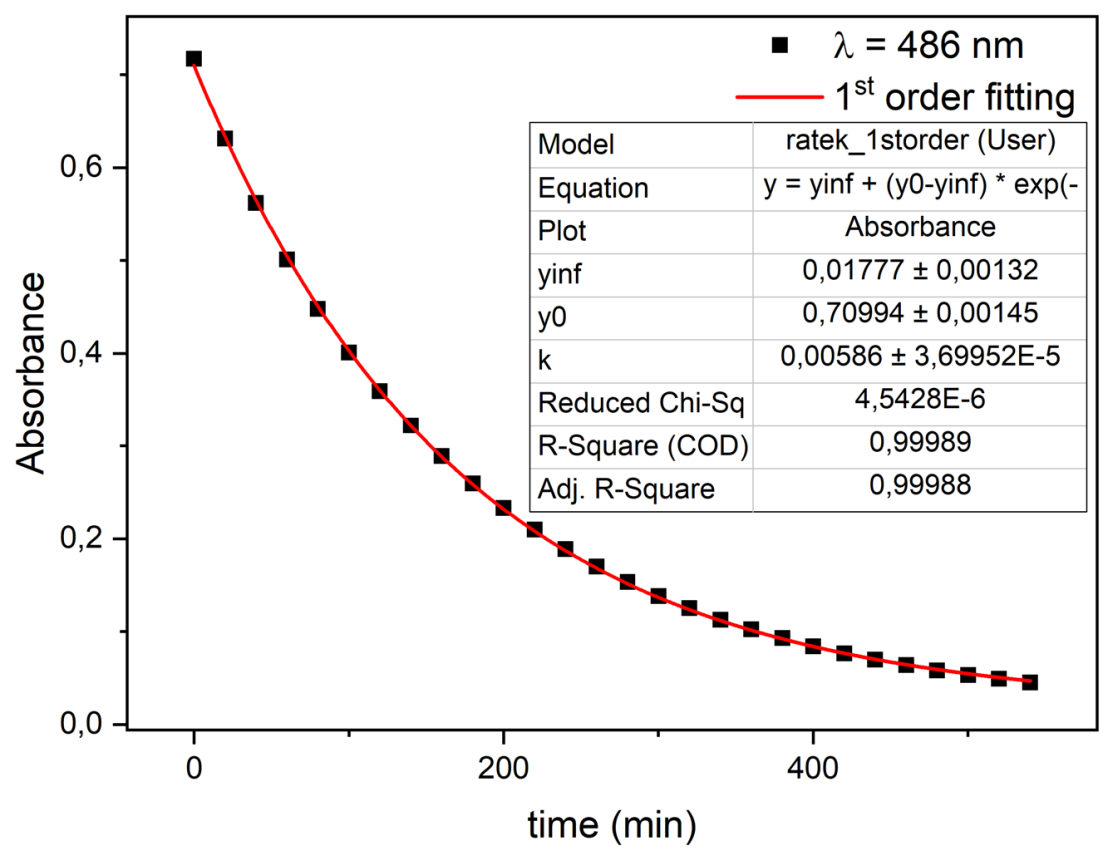

Figure S24. Absorbance decay of trans-L monitored at $\lambda=486 \mathrm{~nm}$ at $\mathrm{T}=308 \mathrm{~K}$ (black squares), and fitting following a $1^{\text {st }}$ order kinetics (red line). 


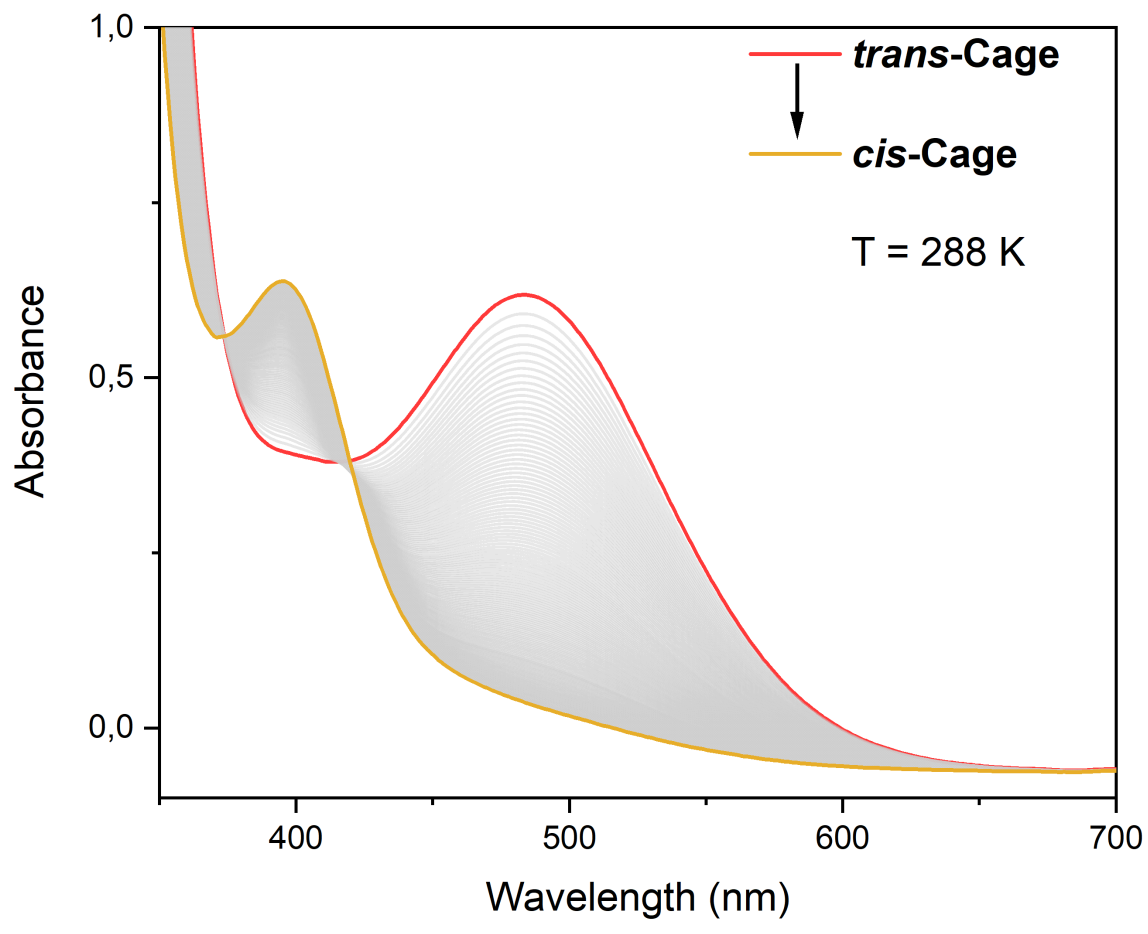

Figure S25. Time dependent UV-Vis spectra at $\mathrm{T}=288 \mathrm{~K}(1.12 \mathrm{mM}$ given as ligand concentration, in DMF), for the thermal relaxation of trans-Cage.

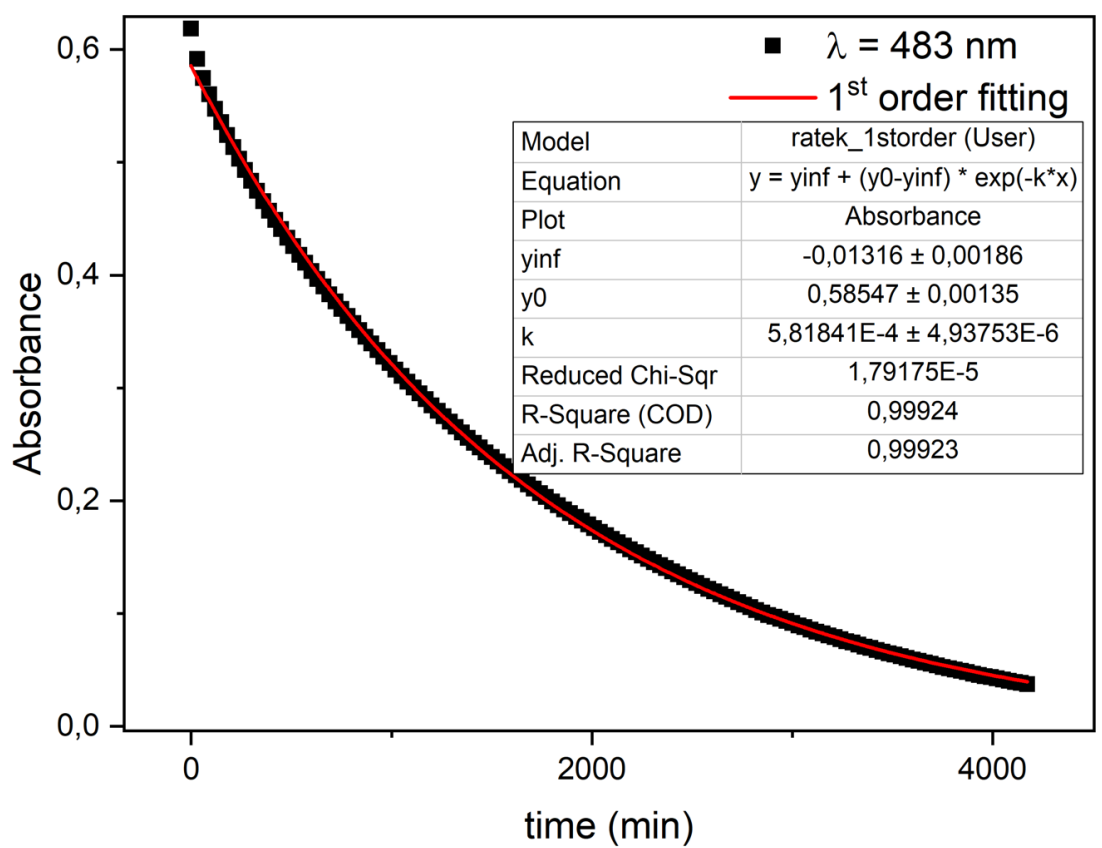

Figure S26. Absorbance decay of trans-Cage monitored at $\lambda=483 \mathrm{~nm}$ at $\mathrm{T}=288 \mathrm{~K}$ (black squares), and fitting following a $1^{\text {st }}$ order kinetics (red line). 


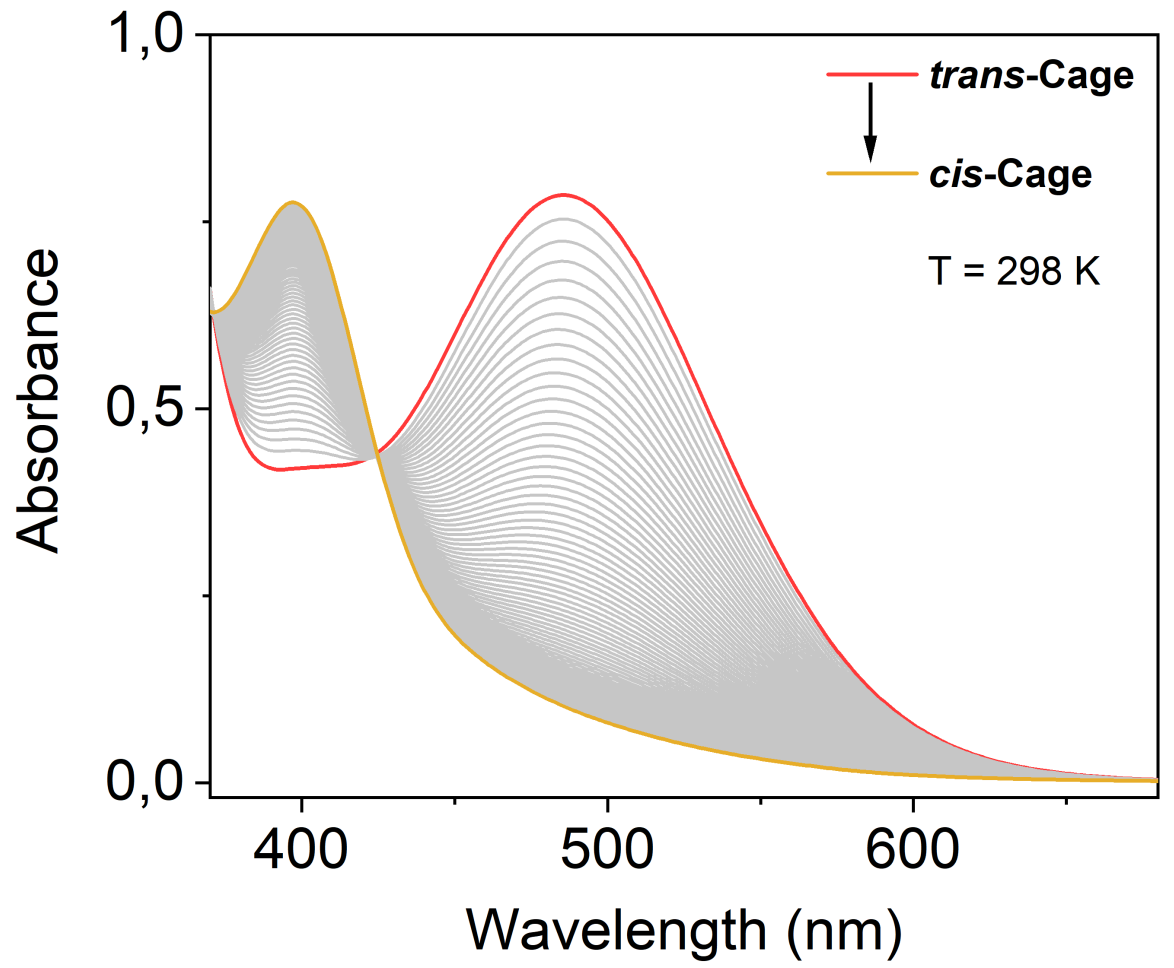

Figure S27. Time dependent UV-Vis spectra at T $=298 \mathrm{~K}(1.12 \mathrm{mM}$ given as ligand concentration, in DMF), for the thermal relaxation of trans-Cage.

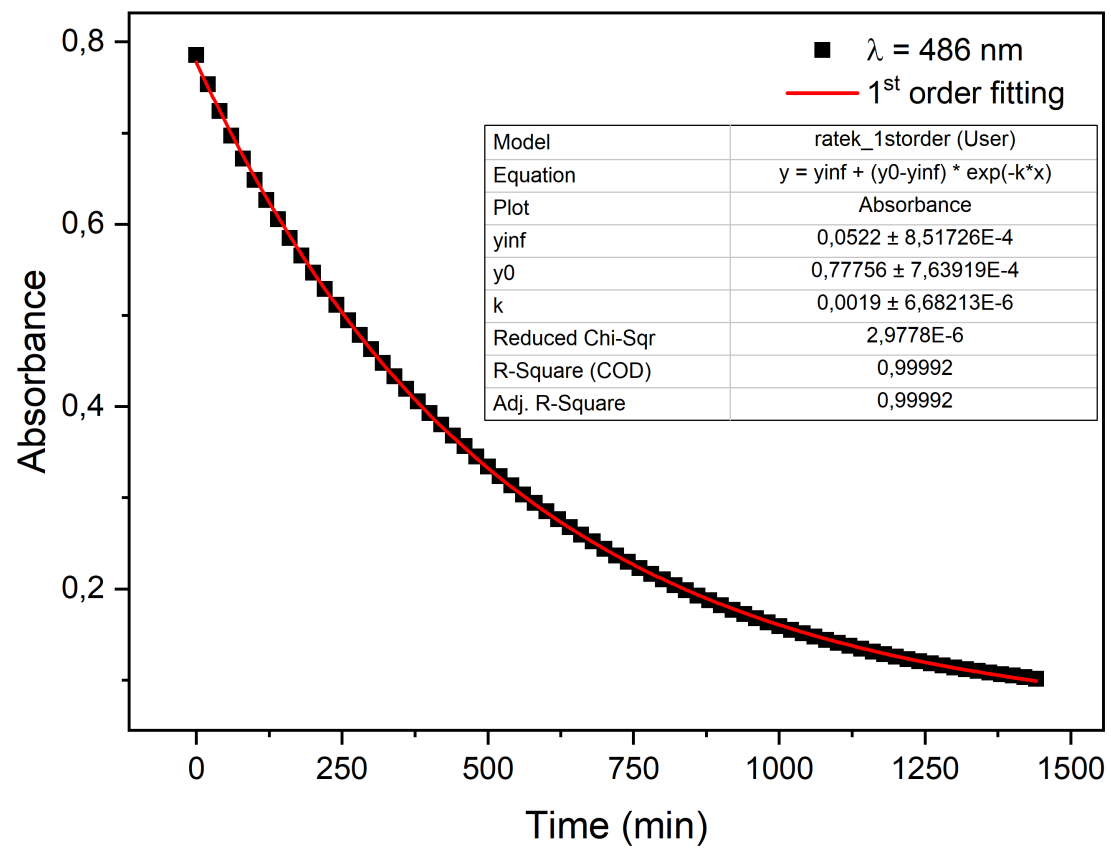

Figure S28. Absorbance decay of trans-Cage monitored at $\lambda=486 \mathrm{~nm}$ at $\mathrm{T}=298 \mathrm{~K}$ (black squares), and fitting following a $1^{\text {st }}$ order kinetics (red line). 


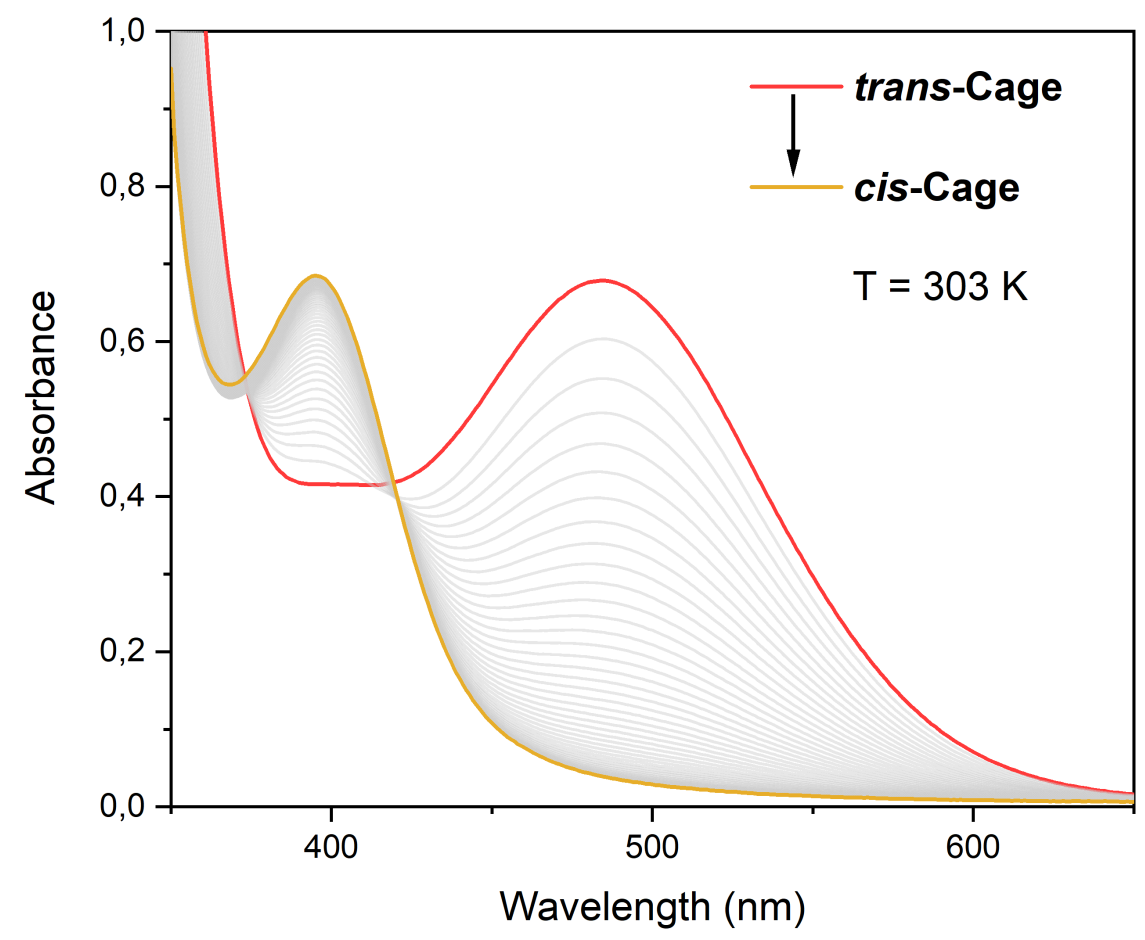

Figure S29. Time dependent UV-Vis spectra at T $=303 \mathrm{~K}(1.12 \mathrm{mM}$ given as ligand concentration, in DMF), for the thermal relaxation of trans-Cage.

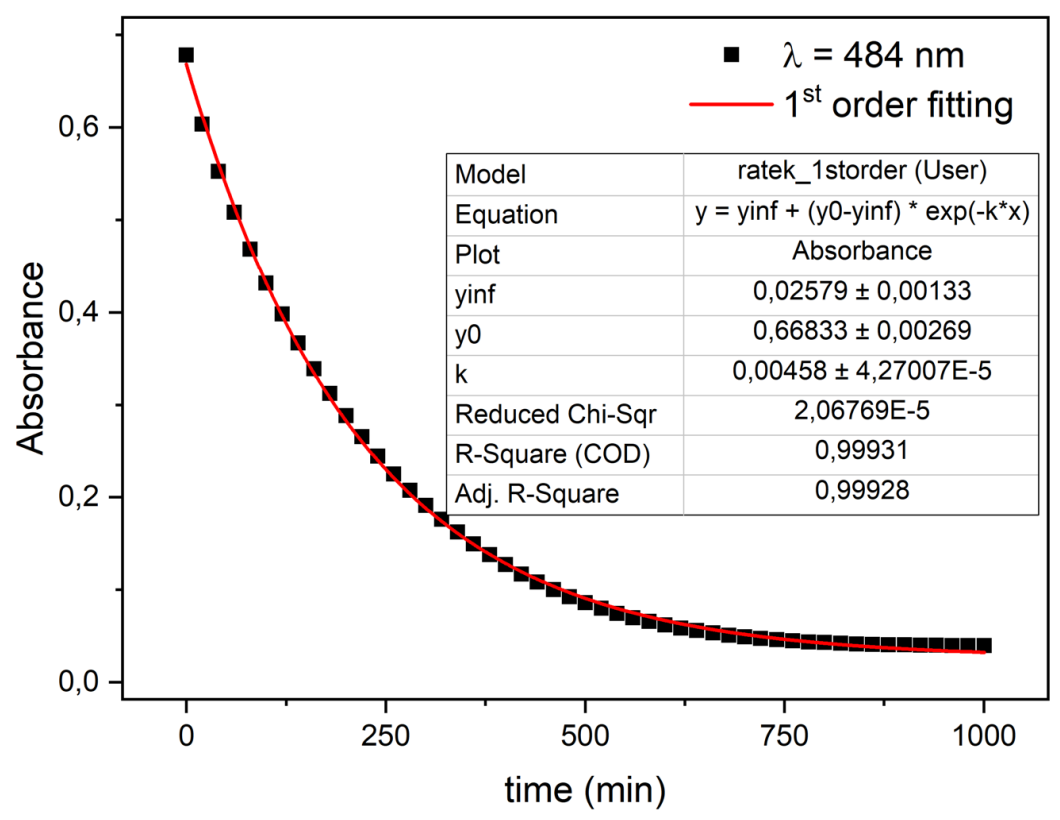

Figure S30. Absorbance decay of trans-Cage monitored at $\lambda=484 \mathrm{~nm}$ at $\mathrm{T}=303 \mathrm{~K}$ (black squares), and fitting following a $1^{\text {st }}$ order kinetics (red line). 


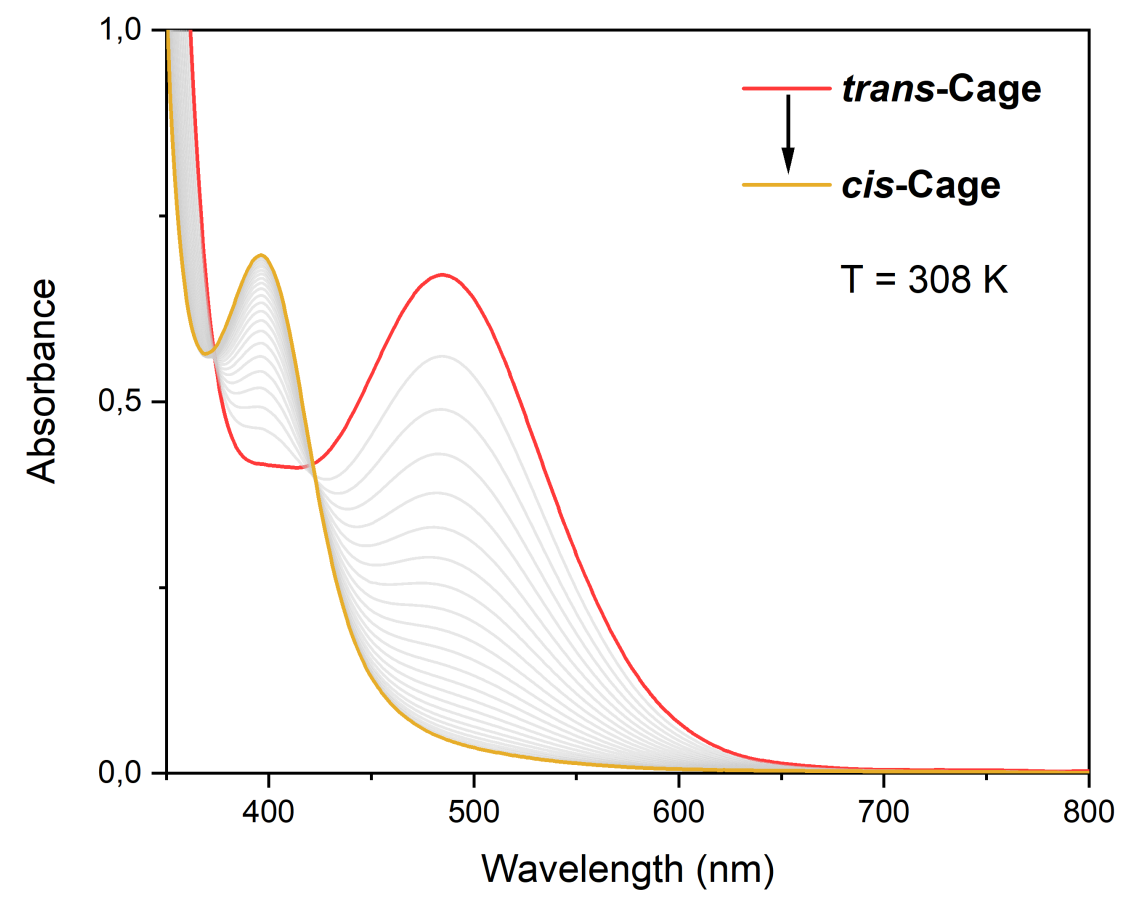

Figure S31. Time dependent UV-Vis spectra at T $=308 \mathrm{~K}(1.12 \mathrm{mM}$ given as ligand concentration, in DMF), for the thermal relaxation of trans-Cage.

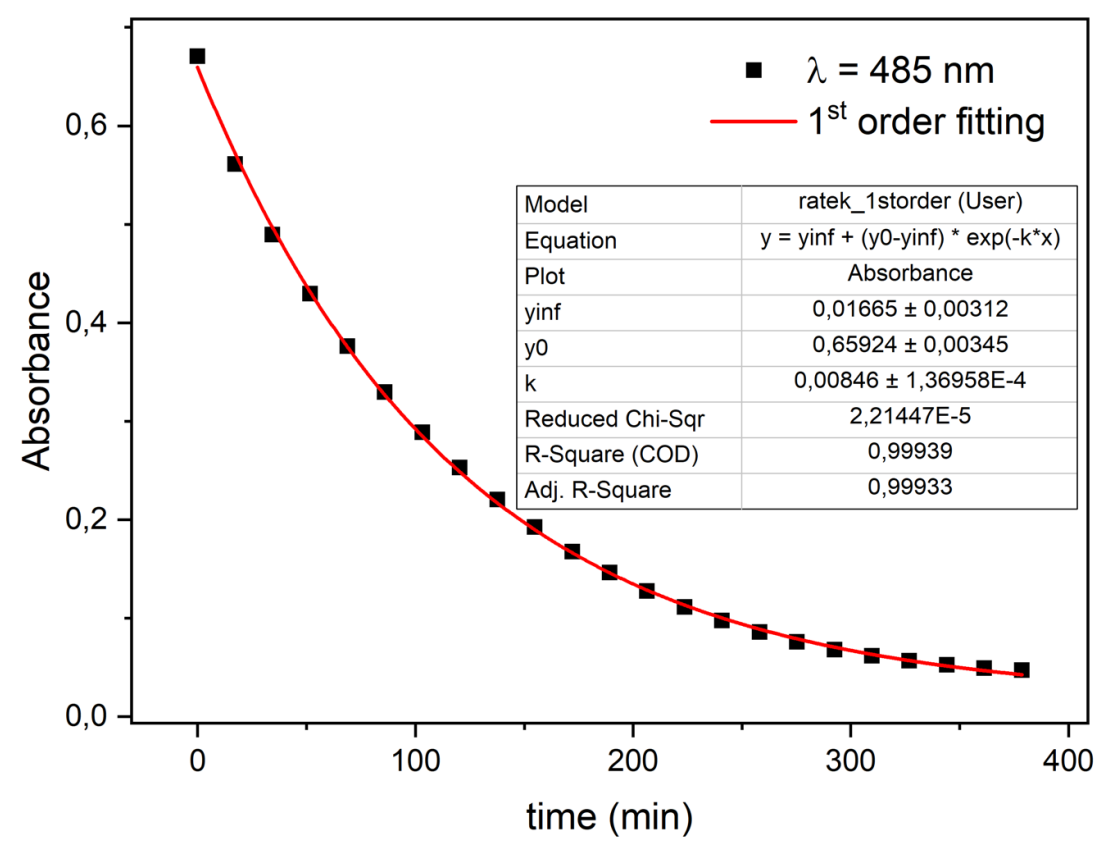

Figure S32. Absorbance decay of trans-Cage monitored at $\lambda=485 \mathrm{~nm}$ at $\mathrm{T}=308 \mathrm{~K}$ (black squares), and fitting following a $1^{\text {st }}$ order kinetics (red line). 

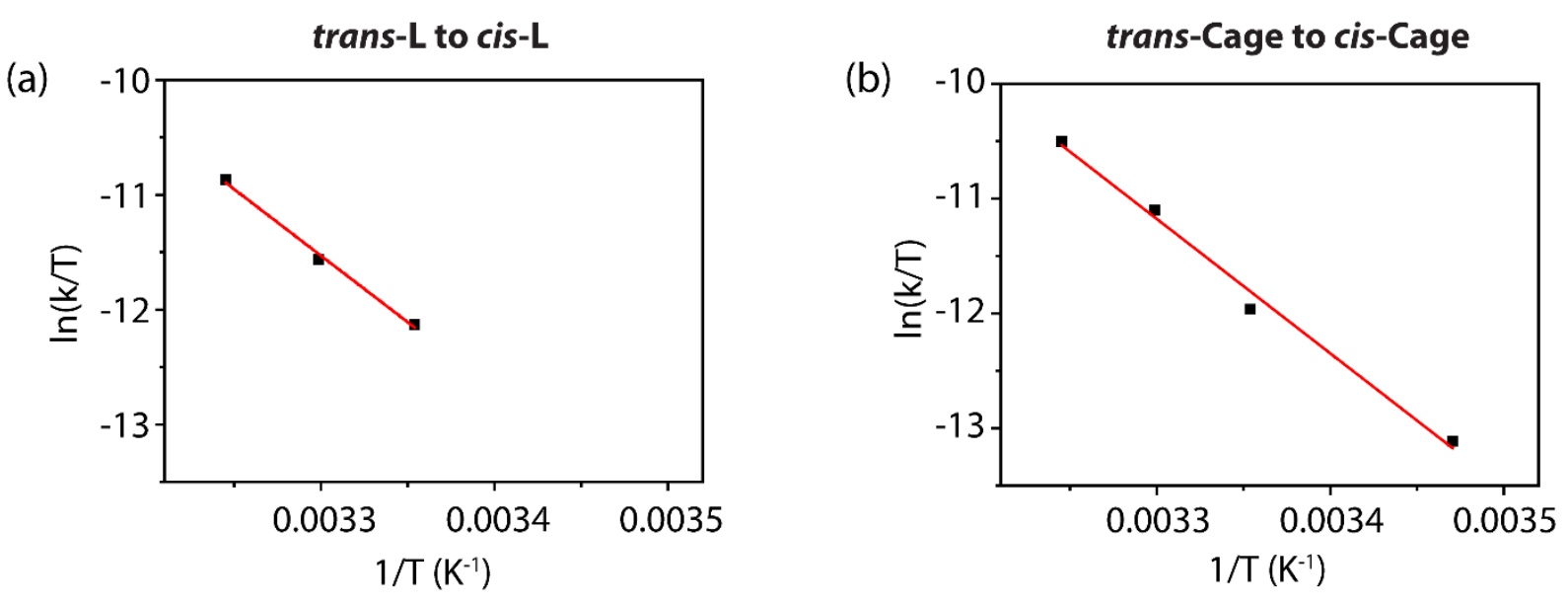

Figure S33. Temperature dependent thermal relaxation process and calculated rate constants and halflife time for trans-L (a) and trans-Cage (b), and activation parameters at $298 \mathrm{~K}$.

trans-L to cis-L

\begin{tabular}{c|cc} 
Temp. $(\mathrm{K})$ & $\begin{array}{c}\text { Rate Constant } \\
\left(\mathrm{mol}_{-1} \mathrm{~min}^{-1}\right)\end{array}$ & Halflife time $(\mathrm{h})$ \\
288 & & \\
298 & $1.6 \times 10^{-3}$ & 7.2 \\
303 & $2.9 \times 10^{-3}$ & 4.0 \\
308 & $5.9 \times 10^{-3}$ & 1.9
\end{tabular}

$$
\text { trans-Cage to cis-Cage }
$$

$\begin{array}{cc}\begin{array}{c}\text { Rate Constant } \\ \left(\text { mol-1 }_{-1}^{-1}\right)\end{array} & \text { Halflife time }(\mathrm{h}) \\ 5.8 \times 10^{-4} & 19.9 \\ 1.9 \times 10^{-3} & 6.1 \\ 4.6 \times 10^{-3} & 2.5 \\ 8.5 \times 10^{-3} & 1.4\end{array}$

Table S1. Calculated rate constants and halflife time for trans-L and trans-Cage.

\begin{tabular}{c|c|c} 
& trans-L to cis-L & trans-Cage to cis-Cage \\
\hline$\Delta \mathrm{H}^{\ddagger}(\mathrm{KJ} / \mathrm{mol})$ & 96.2 & 97.3 \\
$\Delta \mathrm{S}^{\ddagger}(\mathrm{J} / \mathrm{mol} \mathrm{K})$ & 24.2 & 30.7 \\
$-\mathrm{T} \Delta \mathrm{S}^{\ddagger}(\mathrm{KJ} / \mathrm{mol})$ at $298 \mathrm{~K}$ & -7.2 & -9.1 \\
$\Delta \mathrm{G}^{\ddagger}(\mathrm{KJ} / \mathrm{mol})$ at $298 \mathrm{~K}$ & 89.0 & 88.1
\end{tabular}

Table S2. Activation energies for the thermal relaxations of trans-L and trans-Cage. 


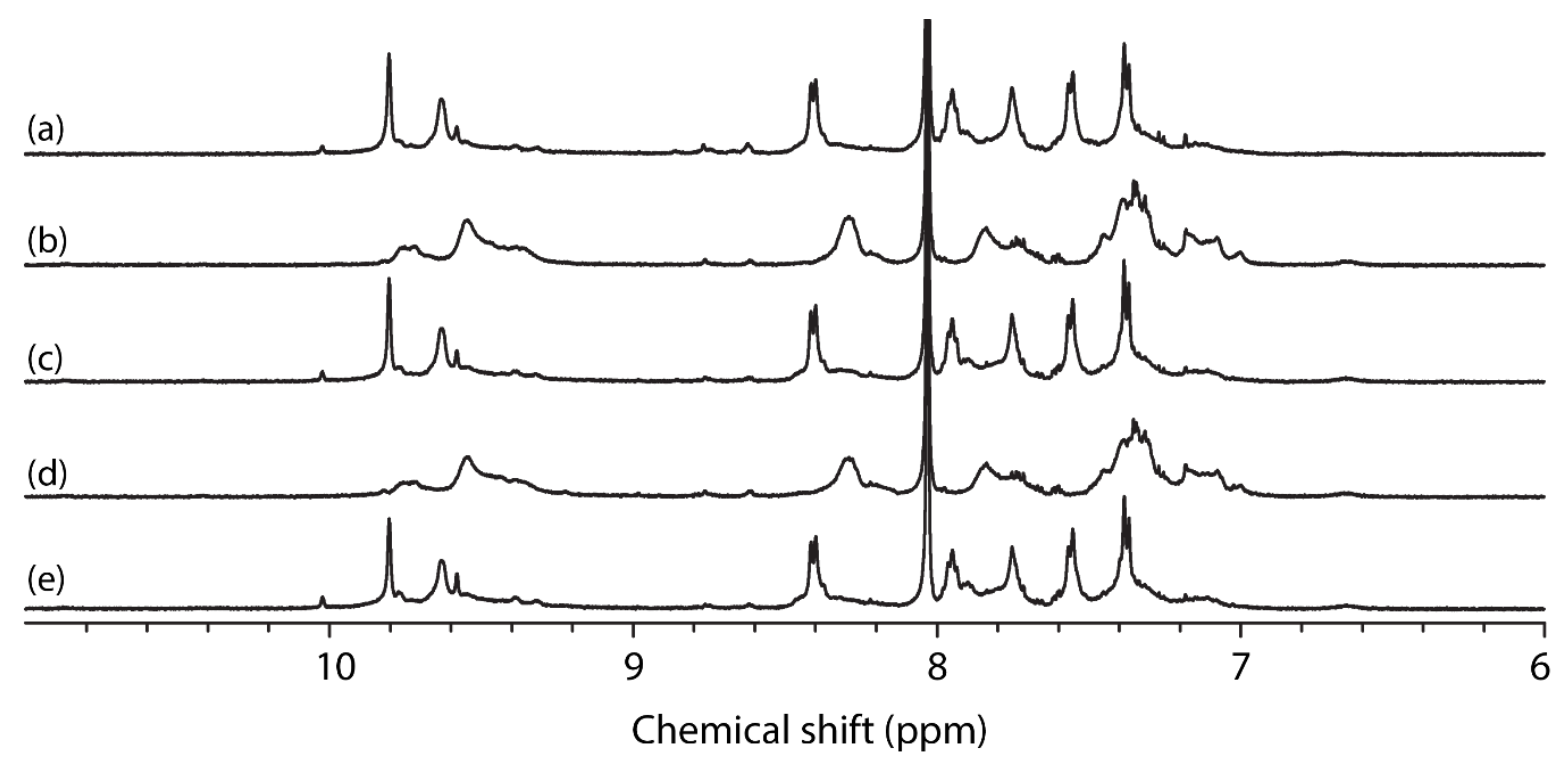

Figure S34. Photoswitching effect by light exposure and thermal relaxation, (a) trans-Cage; (b) sample (a) was kept at room temperature in a dark for $16 \mathrm{~h}$; (c) sample (b) was irradiated at $385 \mathrm{~nm}$ for $10 \mathrm{~min}$; (d) sample (c) under irradiation at $530 \mathrm{~nm}$ for $10 \mathrm{~min}$; (e) sample (d) irradiated at $385 \mathrm{~nm}$ for $10 \mathrm{~min}$.

\section{X-ray crystallography}

\subsection{Crystallization}

\subsubsection{Cis-Ring, $\left[\mathrm{Pd}_{2} \mathrm{Cl}_{4}(\text { cis-L })_{2}\right]$}

Cis-Ring crystals were obtained from slow diffusion in a mixed solution of DMF and $\mathrm{CH}_{2} \mathrm{Cl}_{2}$. After 2 days, block-shaped yellow crystals suitable for X-ray data collection were obtained from the solution.

\subsubsection{Trans-Cage, $\left[\mathrm{Pd}_{2}(\text { trans-L })_{4}\right]\left(B F_{4}\right)_{4}$}

Trans-Cage was crystallized from DMF solution by a slow vapor-phase transfer of diethyl ether in a refrigerator $\left(4^{\circ} \mathrm{C}\right)$ in the dark. After 2 days, red rod-shaped crystals suitable for X-ray diffraction measurement were formed. 


\subsection{Data collection details}

Single crystals for X-ray structural analyses of cis-Ring and trans-Cage were mounted at room temperature in NVH oil. Data were collected in-house on a Bruker D8 Venture diffractometer equipped with an INCOATEC micro focus sealed tube (I $\mu$ s 3.0) using $\mathrm{Mo} K_{\alpha}$ (for cis-Ring), $\mathrm{Cu} K_{\alpha}$ (trans-Cage) for radiation at $100 \mathrm{~K}$. The resolution was cut off at $0.90 \AA$ for cis-Ring, $1.05 \AA$ for trans-Cage, after which the signal to noise ratio has dropped below $\mathrm{I} / \sigma(\mathrm{I})<2.0$. The data was integrated with APEX3. The structures were solved by intrinsic phasing/direct methods using SHELXT ${ }^{[\mathrm{S} 3]}$ and refined with SHELXL $(2018 / 2)^{[\mathrm{S} 4]}$ for full-matrix least-squares routines on $F^{2}$ and ShelXle ${ }^{[\mathrm{S} 5]}$ as a graphical user interface.

\subsubsection{Refinement details for trans-Cage}

Stereochemical restraints for the TDP ligands (trans-L) were generated by the GRADE program using the GRADE Web Server (http://grade.globalphasing.org) and applied in the refinement. A GRADE dictionary for SHELXL contains target values and standard deviations for 1,2-distances (DFIX) and 1,3-distances (DANG), as well as restraints for planar groups (FLAT). All displacements for non-hydrogen atoms were refined anisotropically. The refinement of ADP's for carbon, nitrogen and oxygen atoms was enabled by a combination of similarity restraints (SIMU) and rigid bond restraints (RIGU). ${ }^{[\mathrm{S} 6]}$ The contribution of the electron density from disordered counterions and solvent molecules, which could not be modeled with discrete atomic positions were handled using the SQUEEZE ${ }^{[\mathrm{S} 7]}$ routine in PLATON. ${ }^{\left[{ }^{[8]}\right]}$ The solvent mask file (.fab) computed by PLATON were included in the SHELXL refinement via the ABIN instruction leaving the measured intensities untouched. In the structure, one of ligand backbones is disordered occupying $30 \%$ and $70 \%$ for each part. One $\mathrm{BF}_{4}$ anion and solvent molecules were disordered in positions.

\subsubsection{Refinement details for cis-Ring}

The contribution of the electron density from disordered counterions and solvent molecules, which could not be modeled with discrete atomic positions were handled using the SQUEEZE ${ }^{[\mathrm{S} 7]}$ routine in PLATON. ${ }^{[\mathrm{S} 8]}$ 
Table S3. Crystallographic data of cis-Ring and trans-Cage

\begin{tabular}{|c|c|c|}
\hline & cis-Ring & trans-Cage \\
\hline CCDC No. & 2117885 & 2117884 \\
\hline Empirical formula & $\mathrm{C}_{58} \mathrm{H}_{42} \mathrm{Cl}_{10} \mathrm{~N}_{8} \mathrm{Pd}_{2}$ & $\mathrm{C}_{112} \mathrm{H}_{72} \mathrm{~B}_{4} \mathrm{~F}_{16} \mathrm{~N}_{16} \mathrm{Pd}_{2}$ \\
\hline Formula weight & 1418.29 & 2201.89 \\
\hline Temperature $(\mathrm{K})$ & $173(2)$ & $100(2)$ \\
\hline Wavelength $(\AA)$ & 0.71073 & 1.54178 \\
\hline Crystal system & Triclinic & Triclinic \\
\hline Space group & $P-1$ & $P-1$ \\
\hline Unit cell dimensions, a ( $\AA$ ) & $8.7981(18)$ & $11.9511(12)$ \\
\hline $\mathrm{b}(\AA)$ & $12.744(3)$ & $13.8353(14)$ \\
\hline $\mathrm{c}(\AA)$ & $17.038(3)$ & $26.520(2)$ \\
\hline$\alpha\left(^{\circ}\right)$ & $74.13(3)$ & $75.167(5)$ \\
\hline$\beta\left(^{\circ}\right)$ & $76.99(3)$ & $81.070(5)$ \\
\hline$\gamma\left({ }^{\circ}\right)$ & $76.72(3)$ & $89.999(5)$ \\
\hline Volume $\left(\AA^{3}\right)$ & $1761.4(7) \AA ̊ \Omega 3$ & $4183.9(7)$ \\
\hline $\mathrm{Z}$ & 1 & 1 \\
\hline Density (calculated) $\left(\mathrm{Mg} / \mathrm{m}^{3}\right)$ & 1.337 & 0.874 \\
\hline Absorption coefficient $\left(\mathrm{mm}^{-1}\right)$ & 0.928 & 2.185 \\
\hline $\mathrm{F}(000)$ & 708 & 1112 \\
\hline Crystal size $\left(\mathrm{mm}^{3}\right)$ & $0.150 \times 0.130 \times 0.110$ & $0.150 \times 0.130 \times 0.110$ \\
\hline Theta range for data collection $\left(^{\circ}\right)$ & $\begin{array}{c}1.262 \text { to } 23.252 \\
-9<=\mathrm{h}<=9\end{array}$ & $\begin{array}{c}3.307 \text { to } 47.437 \\
-11<=\mathrm{h}<=11\end{array}$ \\
\hline Index ranges & $\begin{array}{c}-14<=\mathrm{k}<=14 \\
-18<=\mathrm{k}<=18\end{array}$ & $\begin{array}{c}-13<=\mathrm{k}<=13 \\
-25<=1<=25\end{array}$ \\
\hline Reflections collected & 53232 & 34809 \\
\hline Independent reflections & $\begin{array}{c}4946 \\
{[\mathrm{R}(\mathrm{int})=0.0618]}\end{array}$ & $\begin{array}{c}7252 \\
{[\mathrm{R}(\mathrm{int})=0.0875]}\end{array}$ \\
\hline Completeness to theta & $97.80 \%$ & $94.50 \%$ \\
\hline Absorption correction & $\begin{array}{l}\text { Semi-empirical from } \\
\text { equivalents }\end{array}$ & $\begin{array}{l}\text { Semi-empirical from } \\
\text { equivalents }\end{array}$ \\
\hline Max. and min. transmission & 0.903 and 0.870 & 0.7493 and 0.5304 \\
\hline Refinement method & Full-matrix least-squares on $\mathrm{F}^{2}$ & Full-matrix least-squares on $\mathrm{F}^{2}$ \\
\hline Data / restraints / parameters & $4946 / 0$ / 371 & $7252 / 1269 / 813$ \\
\hline Goodness-of-fit on $\mathrm{F}_{2}$ & 1.11 & 1.464 \\
\hline Final $R$ indices $[\mathrm{I}>2 \operatorname{sigma}(\mathrm{I})]$ & $\begin{array}{l}\mathrm{R} 1=0.0484, \\
w \mathrm{R} 2=0.1402\end{array}$ & $\begin{array}{l}\mathrm{R} 1=0.1211, \\
w \mathrm{R} 2=0.3537\end{array}$ \\
\hline $\mathrm{R}$ indices (all data) & $\begin{array}{c}\mathrm{R} 1=0.0517 \\
w \mathrm{R} 2=0.1429\end{array}$ & $\begin{array}{c}\mathrm{R} 1=0.1624, \\
w \mathrm{R} 2=0.3872\end{array}$ \\
\hline Extinction coefficient & $\mathrm{n} / \mathrm{a}$ & $\mathrm{n} / \mathrm{a}$ \\
\hline Largest diff. peak and hole (e. $\left.\AA^{-3}\right)$ & 2.141 and -0.536 & 0.607 and -0.447 \\
\hline
\end{tabular}




\section{DFT calculations}

\subsection{Gas-phase electronic energies for ring conformers}

Gas-phase electronic energies of the experimentally observed $\left[\left(\mathrm{PdCl}_{2}\right)_{2}(\text { cis-L })_{2}\right]^{0}$ ring in its transoid-conformation (with both $\mathrm{N}=\mathrm{N}$ bridges looking into the ring cavity) were compared to other conceivable conformational isomers:

Table S4. Gas phase electronic energies for possible ring conformations formed by two ligands in cis photoisomeric form and two $\mathrm{PdCl}_{2}$ units.

\begin{tabular}{|c|c|c|c|c|c|}
\hline & $\begin{array}{l}\mathrm{E}(\omega \mathrm{B} 97 \mathrm{X}-\mathrm{D} / \\
\mathrm{def} 2-\mathrm{SVP}) / \mathrm{H}\end{array}$ & $\begin{array}{c}\mathrm{E}(\omega \mathrm{B} 97 \mathrm{X}-\mathrm{D} / \\
\mathrm{def} 2-\mathrm{TZVP}) / \mathrm{H}\end{array}$ & $\begin{array}{l}\Delta \mathrm{E}(\mathrm{TZVP}) / \\
\mathrm{kJ} \mathrm{mol}^{-1}\end{array}$ & front view & side view \\
\hline transoid ring & -4686.812447 & -4690.327667 & 0 & & \\
\hline cisoid ring & -4686.812778 & -4690.327737 & -0.18 & & \\
\hline $\begin{array}{c}\text { transoid ring, } \\
\text { one } \mathrm{N}=\mathrm{N} \\
\text { flipped } \\
\text { outwards }\end{array}$ & -4686.811809 & -4690.327034 & 1.66 & & \\
\hline $\begin{array}{c}\text { transoid ring, } \\
\text { both } \mathrm{N}=\mathrm{N} \\
\text { flipped } \\
\text { outwards }\end{array}$ & -4686.810998 & -4690.326204 & 3.84 & & \\
\hline
\end{tabular}

Compared to the experimentally found transoid-geometry, the cisoid isomer is of almost the same energy in these gas-phase calculations but has a much larger dipole moment (0.02 vs. 0.98 D). The transoid isomers with one or both $\mathrm{N}=\mathrm{N}$ bridges flipped outside are 1.7 and $3.8 \mathrm{~kJ} / \mathrm{mol}$ higher in energy.

\subsection{Comparison of strain in cis-Ring, cis-Cage and trans-Cage}

To learn about the enthalpic contributions of the ring-strain that builds up upon assembly of the cis-/trans-ligand isomers with metal precursors $\left[\mathrm{Pd}\left(\mathrm{CH}_{3} \mathrm{CN}\right)_{4}\right]\left(\mathrm{BF}_{4}\right)_{2}$ and $\mathrm{PdCl}_{2}\left(\mathrm{CH}_{3} \mathrm{CN}\right)_{2}$, respectively, we performed a series of gas-phase DFT calculations. 
To estimate the strain energy that is imposed on the ligands by complex formation, the ligand substructures were cut out from the geometry-optimized ring/cages and single-point energies of these structures were compared to the corresponding energies of the fully relaxed (geometry optimized on same level as ring/cages) ligand isomers.

Table S5. Absolute energies [Hartree] of the ligands cis-L and trans-L in their fully optimized geometry and in their geometry in the ring $\left[\left(\mathrm{PdCl}_{2}\right)_{2}(\text { cis-L })_{2}\right]^{0}$ as well as in the cages $\left[\mathrm{Pd}_{2}(\text { cis-L })_{4}\right]^{4+}$ and $\left[\mathrm{Pd}_{2}(\operatorname{trans}-\mathrm{L})_{4}\right]^{4+}$.

$\Delta \mathrm{E}_{\text {ligand }}$ is the energy difference between the fully geometry optimized ligand and the energy of the same ligand in the geometry that it adopts in the corresponding complex (ring or cage).

\begin{tabular}{|c|c|c|}
\hline & $\begin{array}{c}\mathrm{E}(\omega \mathrm{B} 97 \mathrm{X}-\mathrm{D} / \\
\mathrm{def} 2-\mathrm{TZVP}) / \mathrm{H}\end{array}$ & 0 \\
\hline cis-L optimized & -1296.643206 & 4.78 \\
\hline cis-L cut from opt. $\left[\left(\mathrm{PdCl}_{2}\right)_{2}(\text { cis-L })_{2}\right]^{0}$ ring & -1296.641384 & 13.18 \\
\hline cis-L cut from opt. $\left[\mathrm{Pd}_{2}(c i s-\mathrm{L})_{4}\right]^{4+}$ cage & -1296.638185 & \\
\hline & & 0 \\
\hline trans-L optimized & -1296.625722 & 7.37 \\
\hline
\end{tabular}

The cis ligand (cis-L) experiences significantly more strain when incorporated in the cis cage $\left(\left[\mathrm{Pd}_{2}(\text { cis-L })_{4}\right]^{4+}\right)$ than in the cis ring $\left[\left(\mathrm{PdCl}_{2}\right)_{2}(\text { cis-L })_{2}\right]^{0}$. The results are in agreement with the experimental observation that the cis ring is readily formed while the cis cage is only one of many species in a mixture of assembly products. The trans ligand (trans-L) only suffers moderate strain within the trans cage $\left[\operatorname{Pd}_{2}(\text { trans }-\mathrm{L})_{4}\right]^{4+}$, which supports the fact that the trans cage is the major complex formed by the trans ligand in solution.

Additionally, the strain imposed on the coordination sites by the ligands was calculated, by comparing the energies of the $\left.\left[\mathrm{Pd}\left(\mathrm{Cl}_{2}\right) \text { (pyridine }\right)_{2}\right]^{0}$ substructures of the rings and the $\left[\mathrm{Pd}(\text { pyridine })_{4}\right]^{2+}$ substructures of the cages (free valence after formal $\mathrm{C}_{\text {pyridine }}-\mathrm{C}_{\text {ethinyl }}$ bond cleavage saturated with $\mathrm{H}$ ) with the fully optimized structures of $\left[\mathrm{Pd}\left(\mathrm{Cl}_{2}\right)(\text { pyridine })_{2}\right]^{0}$ and $\left[\operatorname{Pd}(\text { pyridine })_{4}\right]^{2+}$. 
Table S6. Absolute energies [Hartree] of the $\left.\left[\mathrm{PdCl}_{2} \text { (pyridine }\right)_{2}\right]^{0}$ and the $\left[\mathrm{Pd}(\text { pyridine })_{4}\right]^{2+}$ unit in their fully optimized geometry and in their geometry in the ring $\left[\left(\mathrm{PdCl}_{2}\right)_{2}(\text { cis-L })_{2}\right]^{0}$ as well as in the cages $\left[\mathrm{Pd}_{2}(\text { cis }-\mathrm{L})_{4}\right]^{4+}$ and $\left[\mathrm{Pd}_{2}(\text { trans }-\mathrm{L})_{4}\right]^{4+} . \Delta \mathrm{E}_{\text {coord. }}$ is the energy difference between the fully geometry optimized coordination site and the energy of the same coordination site in the geometry that it adopts in the corresponding complex (ring or cage).

\begin{tabular}{|c|c|c|}
\hline & $\begin{array}{c}\mathrm{E}(\omega \mathrm{B} 97 \mathrm{X}-\mathrm{D} / \\
\mathrm{def} 2-\mathrm{TZVP}) / \mathrm{H}\end{array}$ & $\Delta \mathrm{E}_{\text {coord. }}\left[\mathrm{kJ} \mathrm{mol}^{-1}\right]$ \\
\hline $\begin{array}{c}{\left[\mathrm{Pd}\left(\mathrm{Cl}_{2}\right)(\text { pyridine })_{2}\right]^{0}} \\
\text { optimized }\end{array}$ & -1545.089916 & 0 \\
\hline $\begin{array}{c}{\left[\mathrm{Pd}\left(\mathrm{Cl}_{2}\right)(\text { pyridine })_{2}\right]^{0} \text { cut from }} \\
{\left[\left(\mathrm{PdCl}_{2}\right)_{2}(\text { (cis-L })_{2}\right]^{0} \text { ring }}\end{array}$ & -1545.088934 & 2.58 \\
\hline & -1120.715382 & 0 \\
\hline$\left[\mathrm{Pd}(\text { pyridine })_{4}\right]^{2+}$ optimized & -1120.711613 & 9.90 \\
\hline $\begin{array}{c}{\left[\mathrm{Pd}(\text { pyridine })_{4}\right]^{2+} \text { cut from }} \\
{\left[\mathrm{Pd}_{2}(\text { cis }-\mathrm{L})_{4}\right]^{4+} \text { cage }}\end{array}$ & -1120.710964 & 11.60 \\
\hline $\begin{array}{c}{\left[\mathrm{Pd}(\text { pyridine })_{4}\right]^{2+} \text { cut from }} \\
{\left[\mathrm{Pd}(\text { trans }-\mathrm{L})_{4}\right]^{4+} \text { cage }}\end{array}$ & & \\
\hline
\end{tabular}

The strain energy imposed on the Pd coordination sites is very low for cis ring $\left(\left[\left(\mathrm{PdCl}_{2}\right)_{2}(\right.\right.$ cisL) 2$]^{0}$ ) and almost 4 times higher for the cis cage. The coordination site is slightly more strained in the trans cage $\left(\left[\mathrm{Pd}_{2}(\text { trans }-\mathrm{L})_{4}\right]^{4+}\right)$ as compared to the cis cage $\left(\left[\mathrm{Pd}_{2}(\text { cis- } \mathrm{L})_{4}\right]^{4+}\right)$. In summary, the calculations predict that the cis ring is favored over the cis cage. If we assume that the total strain energy $\left(E_{\text {strain }}\right)$, in a first approximation, is the sum of the strain energies of the ligands ( $\left.\Delta \mathrm{E}_{\text {ligand }}\right)$ and the coordination sites $\left(\Delta \mathrm{E}_{\text {coord. }}\right): \mathrm{E}_{\text {strain }}=n \cdot \Delta \mathrm{E}_{\text {ligand }}+2 \cdot \Delta \mathrm{E}_{\text {coord. }}$, we obtain a strain energy ( $\mathrm{E}_{\text {strain }}$ ) of the cis cage of $72.5 \mathrm{~kJ} \cdot \mathrm{mol}^{-1}$ and $52.7 \mathrm{~kJ} \cdot \mathrm{mol}^{-1}$ for the trans cage. Hence, the trans cage is significantly less strained than the cis cage.

Absolute and reliable values for the free enthalpy of formation of the complexes are beyond the predictive power of the simple DFT methods used here since entropies and solvent effects are neglected. The interpretation therefore is restricted to the relative energies of very similar systems, where error canceling can be expected to provide reliable trends. 


\section{Host-guest chemistry}

\subsection{General procedure for host-guest titrations}

Host-guest titrations were carried out by stepwise addition of 2,6-naphthalenedisulfonate (G, as tetrabutyl ammonium salt in DMF- $\left.d_{7}\right)$ into a DMF- $d_{7}$ solution of cis- or trans-Cage $(0.7$ $\mathrm{mM}$ ) in an NMR tube. ${ }^{1} \mathrm{H}$ NMR spectra were recorded immediately after vigorous mixing the solution. The titration with trans-Cage (Figure $5 \mathrm{~b}$ in the main text) was conducted in the dark.

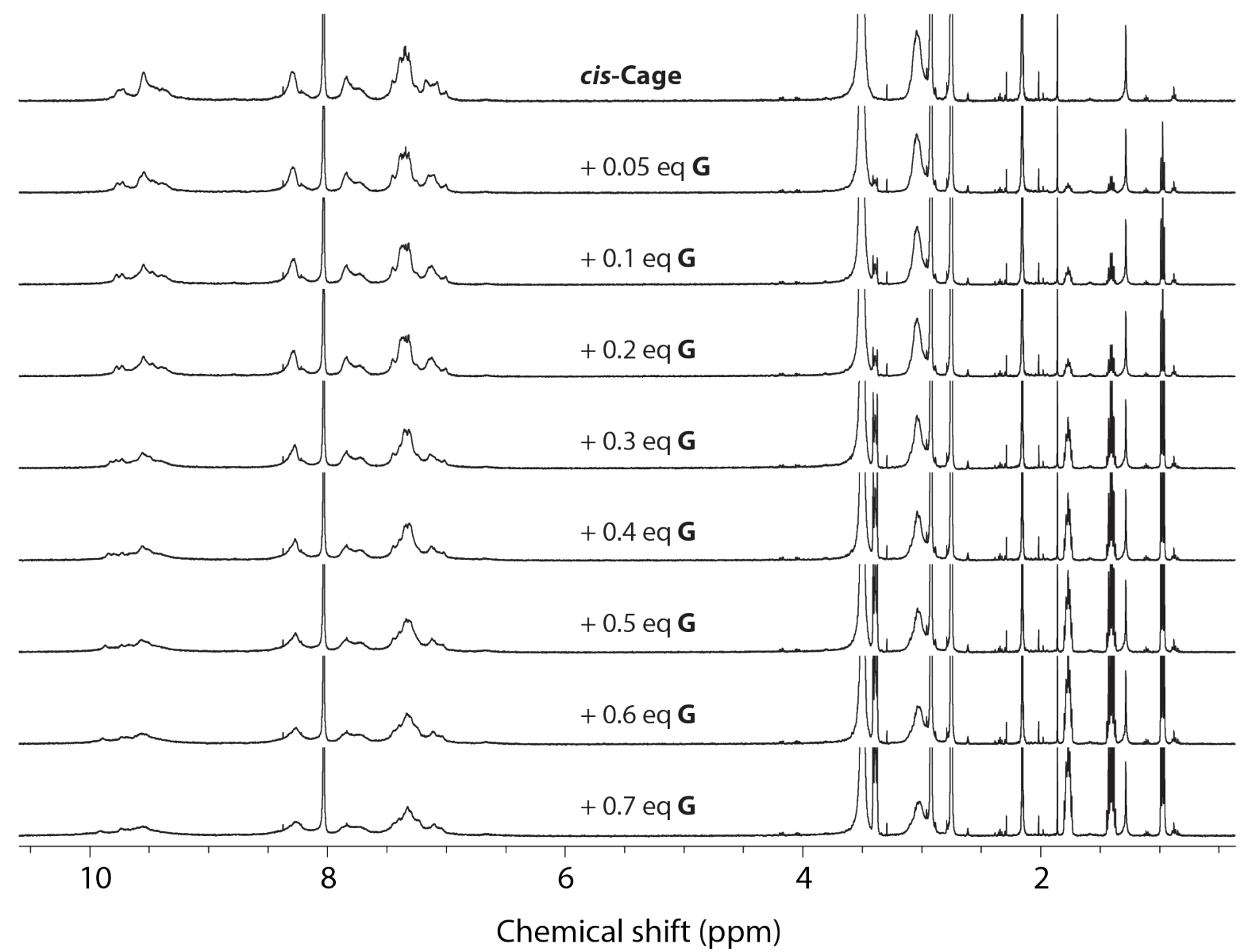

Figure S35. ${ }^{1} \mathrm{H}$ NMR spectra (500 MHz, DMF- $d_{7}$, $298 \mathrm{~K}$ ) for titration experiment of cisCage with G. 


\section{ESI-MS and Ion Mobility spectrometry}

\subsection{General procedure.}

All measurements were performed using a Bruker TIMS-TOF mass spectrometer equipped with electrospray ionization (ESI) source and trapped ion mobility spectrometry (TIMS) set up. Both mass and IMS calibrations were performed using Agilent Tune-Mix ${ }^{\mathrm{TM}}$ as purchased and reported drift tube collision cross section (CCS) by Stow et al. ${ }^{[\mathrm{S} 9]}$ were used for CCS calibration. All samples were diluted with ACN to achieve a final $25 \mu \mathrm{M}$ concentration which were then electrosprayed at $180 \mu \mathrm{L} / \mathrm{h}$ flow rate. The optimized parameters are as following: Capillary voltage: $2500 \mathrm{~V}$, End plate offset: $200 \mathrm{~V}$, Nebulizer: 0.3 bar, Dry gas flow: 3L/min, Dry gas temperature: $75^{\circ} \mathrm{C}$, Funnel 1 RF: 150 V, Funnel 2 RF: 150 V, Multiple RF: 100 V, Deflection delta: $60 \mathrm{~V}$, Transfer time: $70 \mu \mathrm{S}$, Prepulse storage: $15 \mu \mathrm{S}$, Quadrupole ion energy: $7 \mathrm{~V}$ and Collision energy: $5 \mathrm{~V}$. For TIMS, all the ions were accumulated for $5 \mathrm{~s}$ and a $450 \mathrm{~ms}$ ramp time was used. Tunnel in and out pressure were 2.78 mbar and 0.96 mbar, respectively with a pressure difference of 1.82 mbar. In all the measurements the resolving power (CCS/ $\triangle \mathrm{CCS}$ ) was above 180 .

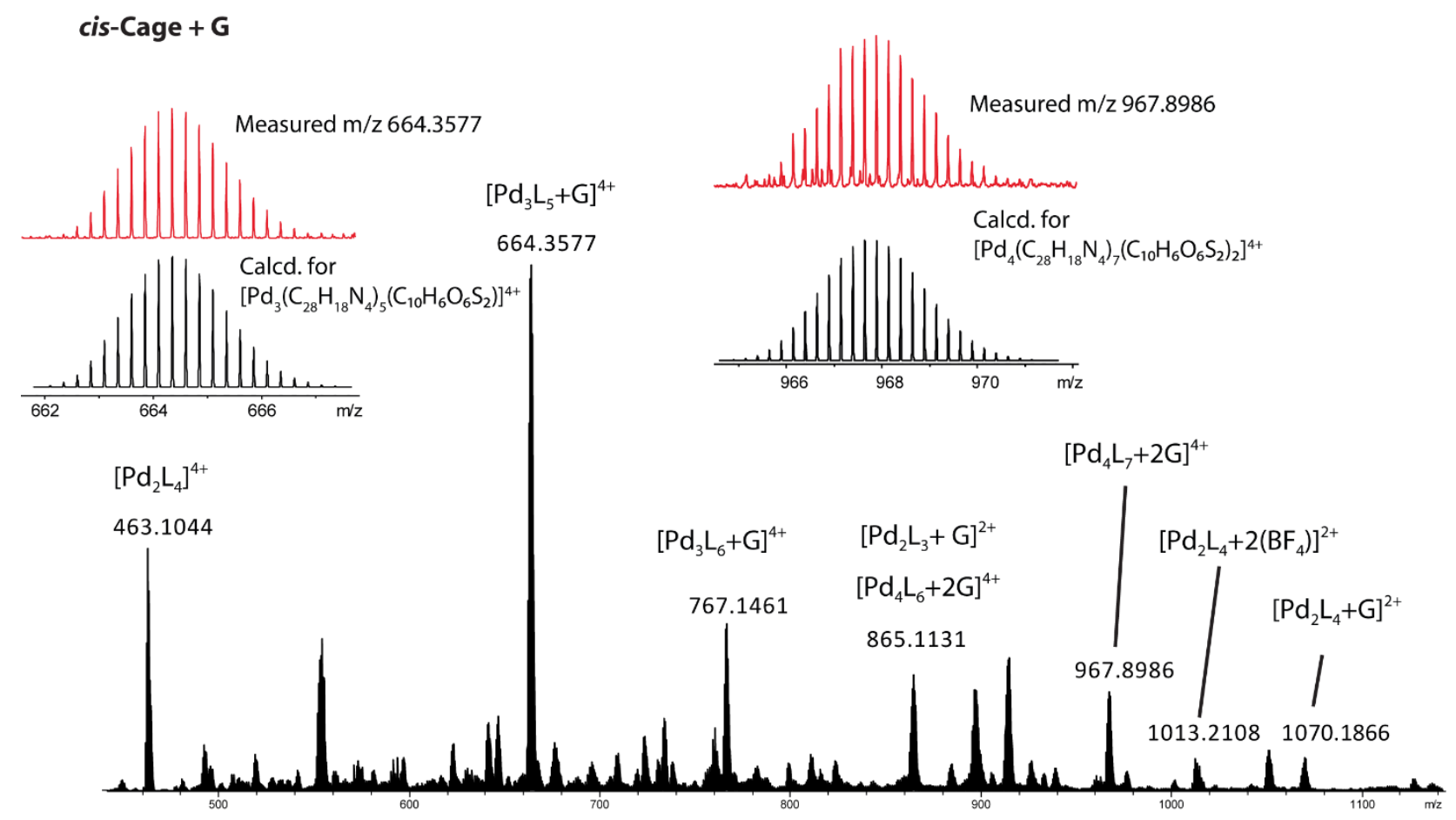

Figure S36. ESI-MS spectrum of cis-Cage with isotopic patterns of $\left[\mathrm{Pd}_{3} \text { cis- } \mathbf{L}_{5}+\mathbf{G}\right]^{4+}$ and $\left[\mathrm{Pd}_{4} \text { cis- } \mathbf{L}_{7}+2 \mathbf{G}\right]^{4+}$ shown in the inset. 


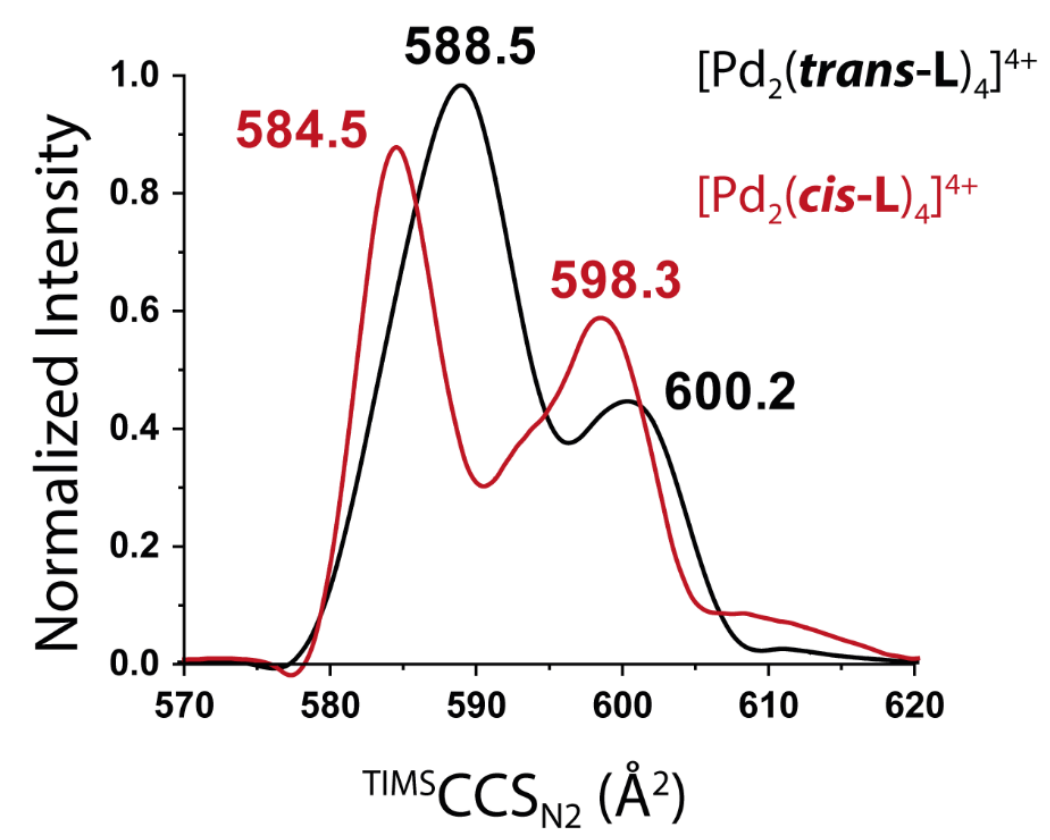

Figure S37. CCS values for cis-Cage (red line) trans-Cage (black line) measured for the signal corresponding to the $\left[\mathrm{Pd}_{2}(\mathrm{~L})_{4}\right]^{4+}$ species at $463.11 \mathrm{~m} / \mathrm{z}$.

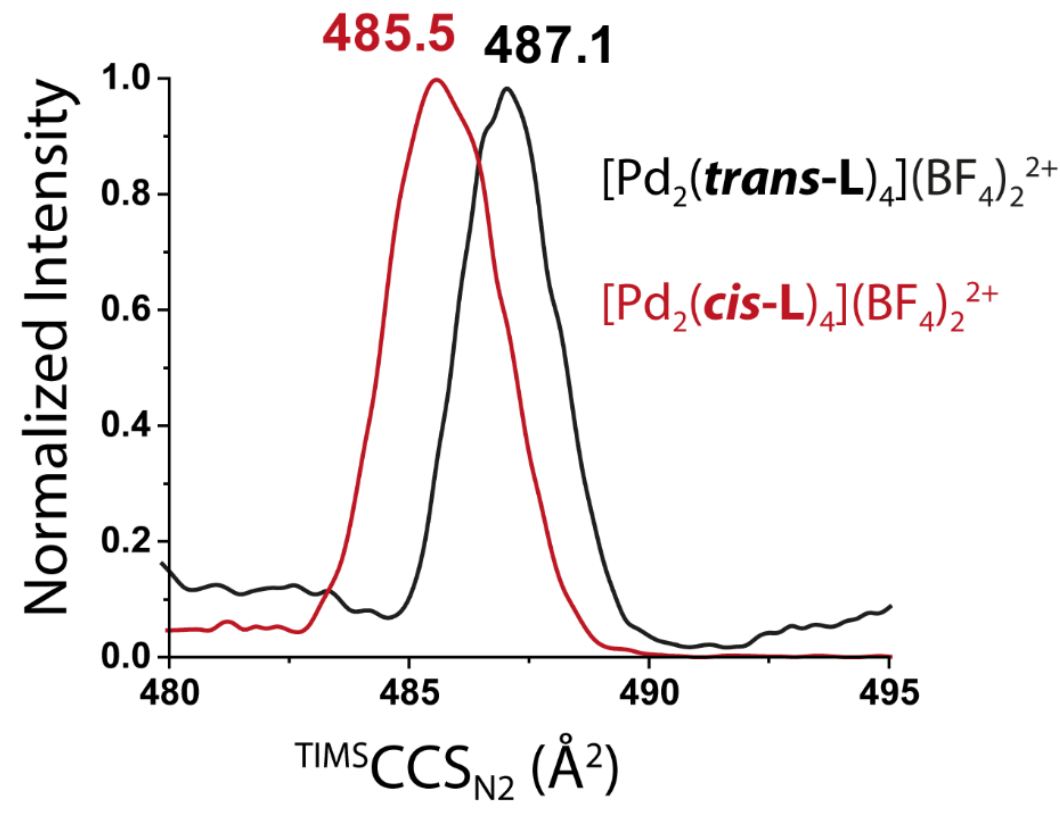

Figure S38. CCS values for cis-Cage (red line) trans-Cage (black line) measured for the signal corresponding to the $\left[\mathrm{Pd}_{2}(\mathrm{~L})_{4}\right]\left(\mathrm{BF}_{4}\right)_{2}{ }^{2+}$ species at $1013.21 \mathrm{~m} / \mathrm{z}$. 


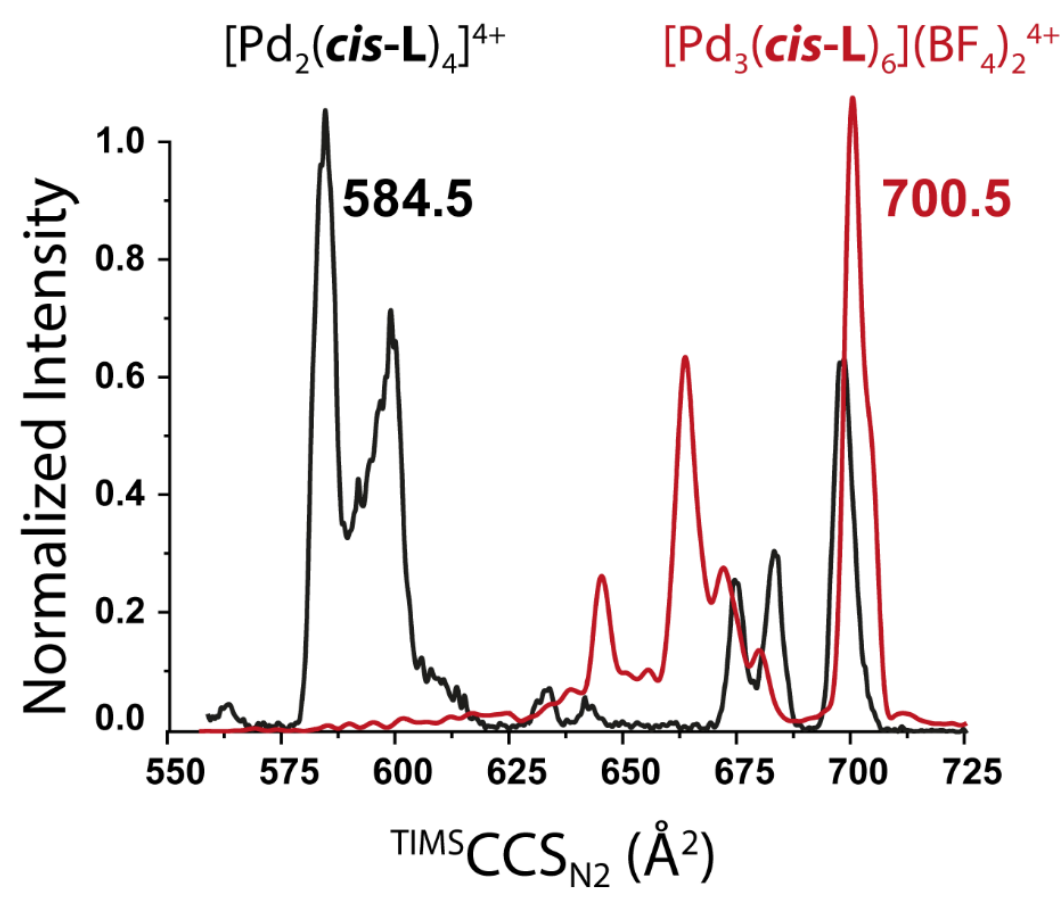

Figure S39. Comparison of the CCS values for cis-Cage signals corresponding to the 4+ species with formula $\left[\mathrm{Pd}_{2}(\mathrm{~L})_{4}\right]^{4+}\left(463.11 \mathrm{~m} / \mathrm{z}\right.$, black line), and $\left[\mathrm{Pd}_{3}(\mathrm{~L})_{6}\right]\left(\mathrm{BF}_{4}\right)_{2}{ }^{4+}(738,91 \mathrm{~m} / \mathrm{z}$, red line).
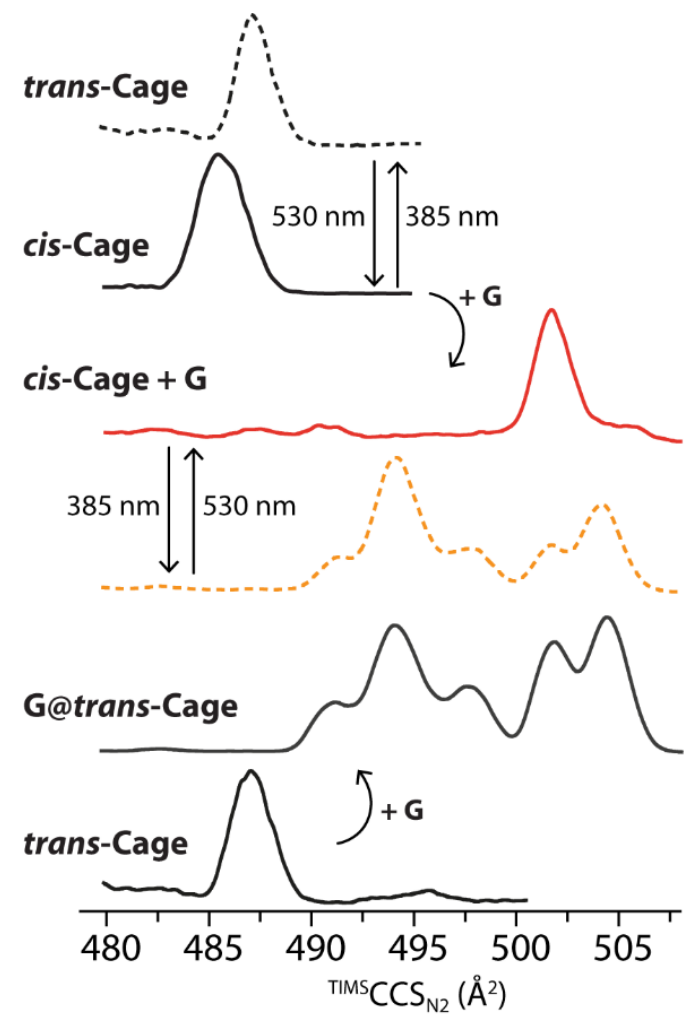

Figure S40. CCS values for cis-Cage and trans-Cage with and without the addition of the guest and upon irradiation. Signals corresponding to the $2+$ species, with formula $\left[\mathrm{Pd}_{2}(\mathrm{~L})_{4}\right]\left(\mathrm{BF}_{4}\right)_{2}{ }^{2+}$ $(1013.21 \mathrm{~m} / \mathrm{z})$ and $\left[\mathrm{Pd}_{2}(\mathrm{~L})_{4}+\mathrm{G}\right]^{2+}(1070.18 \mathrm{~m} / \mathrm{z})$. 


\section{References}

[S1] Moormann, W., Langbehn, D., Herges, R. Beilstein J. Org. Chem. 2019, 15, 727.

[S2] Clever, G. H., Kawamura, W. Shionoya M. Inorg. Chem. 2011, 50, 4689.

[S3] Sheldrick, G. M. Acta Crystallogr. Sect. A, 2015, 71, 3.

[S4] Sheldrick, G. M. Acta Crystallogr. Sect. C, 2015, 71, 3.

[S5] Hübschle, C. B. Sheldrick, G. M., Dittrich, B. J. Appl. Cryst., 2011, 44, 1281.

[S6] Thorn, A., Dittrich, B., Sheldrick, G. M. Acta Crystallogr. Sect. A 2012, 68, 448-451.

[S7] Spek, A. Acta Crystallogr. Sect. C, 2015, 71, 9.

[S8] Spek, A. Acta Crystallogr. Sect. D, 2009, 65, 148.

[S9] Stow, S. M., Causon, T. J., Zheng, X., Kurulugama, R.T., Mairinger, T., May, J. C., Rennie, E. E., Baker, E. S., Smith, R. D., McLean, J. A., Hann, S., Fjeldsted, J. C. Anal. Chem., 2017, 89, 9048. 